\title{
Electrochemical, Surface-Analytical, and Computational DFT Study of Alkaline Etched Aluminum Modified by Carboxylic Acids for Corrosion Protection and Hydrophobicity
}

\author{
I. Milošev, $\oplus^{1, *, z}$ T. Bakarič, ${ }^{1}$ S. Zanna, ${ }^{2}$ A. Seyeux, ${ }^{2}$ P. Rodič, ${ }^{1}$ M. Poberžnik, ${ }^{1}{ }^{1}$ F. Chiter, ${ }^{2}$ \\ P. Cornette, ${ }^{2}$ D. Costa, ${ }^{2}$ A. Kokalj, ${ }^{1}{ }^{1}$ and P. Marcus ${ }^{2, * *, z}$ \\ ${ }^{1}$ Jožef Stefan Institute, Department of Physical and Organic Chemistry, SI-1000 Ljubljana, Slovenia \\ ${ }^{2}$ PSL Research University, CNRS - Chimie ParisTech, Institut de Recherche de Chimie Paris (IRCP), Physical \\ Chemistry of Surfaces Group, 75005 Paris, France
}

\begin{abstract}
Carboxylic acids were investigated as a means to fabricate a superhydrophobic and corrosion resistant aluminum surface. Alkaline etching produced a hierarchically rough, superhydrophilic and hydroxylated $\mathrm{Al}$ surface which could then be modified by immersion in ethanol solution of carboxylic acids of different alkyl chain lengths, from hexanoic to octadecanoic. Acids with chain length longer than seven carbon atoms acted as corrosion inhibitors, but only those with long chains (e.g., octadecanoic acid) acted as a corrosion barrier and made the surface superhydrophobic with water contact angles over 150 degrees. The morphology, topography and chemical composition of unmodified $\mathrm{Al}$ and etched $\mathrm{Al}$ modified by carboxylic acids were studied using surface analytical tools (scanning electron microscopy with chemical analysis, X-ray photoelectron spectroscopy, and time-of-flight secondary ion mass spectrometry). Modelling based on density functional theory was performed to help explain experimental observations and to provide a rationale of why only carboxylic acids with long enough chains were effective in reducing the rate of corrosion. The reason was attributed to their ability to form more stable and protective organic films. Aluminum surface prepared under appropriate conditions was superhydrophobic, corrosion resistant and durable and showed self-cleaning and delayed ice-melting properties. (c) The Author(s) 2019. Published by ECS. This is an open access article distributed under the terms of the Creative Commons Attribution 4.0 License (CC BY, http://creativecommons.org/licenses/by/4.0/), which permits unrestricted reuse of the work in any medium, provided the original work is properly cited. [DOI: 10.1149/2.0181911jes]

(cc) BY
\end{abstract}

Manuscript submitted February 15, 2019; revised manuscript received April 9, 2019. Published April 25, 2019. This was Paper 787 presented at the National Harbor, Maryland Meeting of the Society, October 1-5, 2017. This paper is part of the JES Focus Issue on Advanced Techniques in Corrosion Science in Memory of Hugh Isaacs.

The interest in superhydrophobic surfaces has been rising considerably as reflected by numerous review papers published in the last decade. ${ }^{1-13}$ Surfaces of different materials, such as metals, composites, tiles, textiles, and tissues, can be made superhydrophobic. These are then used in a variety of industrial and every-day applications including electronic industry (ultra-dry surface applications, sensors, optical devices), water-repellent textile, removal of dirt particles along with rolling liquid droplets (self-cleaning), prevention of formation and accumulation of ice on the surface (anti-icing), prevention of aggressive medium to get into contact with metal surface (corrosion prevention), reduced biofouling on ships' hulls and consequently reduced friction and fuel consumption (drag-reduction), windshield and window protection from fogging rain droplets (anti-fogging), improved performance of water desalination systems by increasing flux in membrane distillation, preventing bacterial attachment (anti-bacterial), oil and water separation, etc. This variety of applications stems from the fact that superhydrophobic surfaces bring additional functionalization of the material by using relatively simple and usually inexpensive methods and procedures which can be up-scaled. Especially valuable are fabrication methods which tend to avoid the use of chemicals that are proven to be, or are potentially harmful for the environment and humans.

Superhydrophobic surfaces, i.e., those which have a tendency to repel water drops, are characterized by a high apparent contact angle, $\left(\theta>150^{\circ}\right)$, low contact angle hysteresis $\left(<10^{\circ}\right)$, and low sliding angle $\left(\alpha<5^{\circ}\right) \cdot{ }^{1-3}$ Superhydrophobicity of the surface is achieved by an appropriate combination of surface roughness, texture, and low surface energy. On flat surfaces, wettability can be increased by a coating of low surface energy. Examples include alkyl and perfluoro functional groups which decrease surface energy in the order $-\mathrm{CH}_{2}->-\mathrm{CH}_{3}$ $>-\mathrm{CF}_{2}->-\mathrm{CF}_{2} \mathrm{H}->-\mathrm{CF}_{3}{ }^{1}$ Even when these groups are closely packed at the surface the maximum $\theta$ cannot exceed $130^{\circ} .{ }^{1}$ For rough

\footnotetext{
*Electrochemical Society Member

**Electrochemical Society Fellow.

${ }^{\mathrm{z} E}$ E-mail: ingrid.milosev@ijs.si; philippe.marcus@chimie-paristech.fr
}

surfaces, the wettability regime can follow two models: (i) the Wenzel model describes the change in $\theta$ as a function of roughness on a liquid-wetted surface; roughness either promotes wettability $(\theta<$ $\left.90^{\circ}\right)$ or non-wettability $\left(\theta>90^{\circ}\right)$ depending on the chemical nature of the substrate, i.e., increasing roughness of a hydrophobic surface renders it more hydrophobic, but on a hydrophilic surface it causes the opposite effect, i.e., it becomes more hydrophilic. (ii) The CassieBaxter model describes the change in $\theta$ as a function of roughness on a surface covered by small protrusions filled by air (which is hydrophobic); when wetted, the liquid cannot fill these pockets and the contact area between substrate and liquid is greatly reduced leading to superhydrophobicity. In the Cassie-Baxter model $\theta$ increases with surface roughness irrespective of its chemical composition and can reach values over $150^{\circ} .1,2$

Fabrication methods usually combine two approaches: top down and bottom-up. ${ }^{1-13}$ The top-down approach includes the removal of surface material to create appropriate surface roughness and texture, e.g. lithography, machining, plasma treatment, chemical etching ${ }^{12}$ followed by coating the surface using hydrophobic chemical compounds of low surface energy. Bottom-up approach refers to a material addition process or self-assembly by building blocks of nano- or microfabrication: chemical vapor deposition, electrochemical deposition, layer-by-layer deposition, and the sol-gel method. Methodology of fabrication of superhydrophobic surfaces is versatile and already able to produce corrosion resistant surfaces ${ }^{5,9,13}$ but future work should be focused on mechanical, i.e., abrasive resistance of such surfaces, their chemical stability in media of different $\mathrm{pHs}$, as well as long-term corrosion performance.

The subject of this study is the fabrication of a superhydrophobic aluminum surface. Aluminum is becoming an increasingly important metal in transportation (automobile, airplane and marine) and civil engineering industries. Aluminum and Al-based alloys are spontaneously protected by a native oxide layer which, however, cannot resist harsh environment and needs to be additionally protected. ${ }^{14}$ Harsh environment refers to chloride containing media and also to media with either low or high $\mathrm{pH}$ that is outside the stability region of the native oxide $(4<\mathrm{pH}<8.5) .{ }^{14}$ Such harsh conditions are used during 
cleaning of different Al-based products with alkaline protocols. Superhydrophobicity of $\mathrm{Al}$ and $\mathrm{Al}$-alloys is attracting increasing interest because of the possibility to improve their corrosion resistance using non-chromate protective coatings, as chromate conversion coatings are abandoned due to ecological risk. ${ }^{15}$ Moreover, additional functional properties, e.g. self-cleaning and anti-icing, represent added value compared to traditional corrosion resistant coatings like conversion and phosphate coatings. Several strategies have been hitherto explored to fabricate superhydrophobic Al-based surfaces, including sol-gel and spray coatings. ${ }^{16-18}$ The most common approach was to use a two-step process including roughening of the Al surface followed by grafting of low-energy silane-based ${ }^{19}$ or fluorinated ${ }^{20-22}$ compounds. Surface roughening was induced by acid etching, ${ }^{19,21}$ but also alkaline etching followed by metal chloride $\left(\mathrm{FeCl}_{3}\right)$ etching. ${ }^{22}$ Etching of $\mathrm{Al}$ in $\mathrm{NaOH}$ and $\mathrm{CuCl}_{2}$ itself can produce a superhydrophobic surface but only after thermal treatment resulting in the formation of nanosized particles of $\mathrm{CuO}$ and $\mathrm{Al}_{2} \mathrm{O}_{3} \cdot{ }^{23}$ Similarly, immersion of $\mathrm{Al}$ in chloroauric acid $\left(\mathrm{HAuCl}_{4}\right)$ and subsequent annealing treatment at $180^{\circ} \mathrm{C}$ produced a superhydrophobic $\mathrm{Al}-\mathrm{AlAu}_{4}-\mathrm{Al}_{2} \mathrm{O}_{3}$ surface. ${ }^{24}$ The electrochemical process of anodic oxidation was also often used as a surface preparation step prior to chemical modification. Aluminum anodized in oxalic acid, immersed in fluorinated silane and dried for $60 \mathrm{~min}$ at $120^{\circ} \mathrm{C}$ exhibited $\theta>163^{\circ}$ and $\alpha<2^{\circ} .^{25}$ An oil-infused slippery Al surface was obtained by electrochemical etching in $\mathrm{NaCl}$ followed by anodic oxidation in a mixture of oxalic acid and $\mathrm{Al}_{2} \mathrm{O}_{3}{ }^{26}$

In order to fabricate superhydrophobic aluminum we used carboxylic acids (CAs), $\mathrm{CH}_{3}\left(\mathrm{CH}_{2}\right)_{n} \mathrm{COOH}$, as a means to achieve a low-energy surface. In our previous publications CAs of different chain length (number of carbon atoms from 6 to 18) were used as individual corrosion inhibitors for $\mathrm{Cu}, \mathrm{Zn}$ and brasses. ${ }^{27}$ Furthermore, stearic (octadecanoic) acid, being the most efficient among the investigated CAs, was also combined with benzotriazole and 2-mercaptobenzotriazole to produce mixed inhibitor layers showing both corrosion resistance and hydrophobicity. ${ }^{28-31}$ Myristic (tetradecanoic) acid was also tested as a promising treatment for protection of copper and bronze artefacts. ${ }^{32,33}$ Long-chain CAs have been previously used in other studies to fabricate corrosion resistant and/or hydrophobic surfaces on different metals such as $\mathrm{Cu},{ }^{34} \mathrm{Mg},{ }^{35}$ and $\mathrm{Zn}^{36} \mathrm{Al}$ anodized in sulphuric acid, immersed in myristic acid at $70^{\circ} \mathrm{C}$ for $30 \mathrm{~min}$ and dried at $80^{\circ} \mathrm{C}$ showed $\theta>150^{\circ}$ and was protective in chloride solution ${ }^{37-39}$ and reduced bacteria attachment. ${ }^{40}$ Good corrosion resistance of the coating was ascribed to the formation of chemically bonded carboxylate, i.e., $\mathrm{Al}\left[\mathrm{CH}_{3}\left(\mathrm{CH}_{2}\right)_{12} \mathrm{COO}\right]_{3}$. A similar compound was produced by immersion of $\mathrm{Al}$ in myristic acid and $\mathrm{Al}\left(\mathrm{NO}_{3}\right)_{3}$ followed by anodization. ${ }^{41}$ In another study, aluminum alloy AA6061 was first anodized in phosphoric acid and then a superhydrophobic coating was formed by electrodeposition in the solution of stearic acid and $\mathrm{Zn}\left(\mathrm{NO}_{3}\right)_{2} \cdot{ }^{42} \mathrm{~A}$ coating consisting of $\mathrm{Ce}\left[\mathrm{CH}_{3}\left(\mathrm{CH}_{2}\right)_{12} \mathrm{COO}\right]_{3}$ was prepared on $\mathrm{Al}$ by electrodeposition from $\mathrm{Ce}\left(\mathrm{NO}_{3}\right)_{3}$ and hexadecanoic acid. ${ }^{43}$ Excellent durability and corrosion resistance was noted. Similarly, superhydrophobic coatings were prepared by boiling in $\mathrm{NaOH}$ followed by immersion in lauric (dodecanoic) acid, ${ }^{44}$ acid etching or anodic oxidation followed by immersion in stearic acid, ${ }^{45}$ and acid etching in $\mathrm{HCl}$ followed by hydrophobization by ceria-stearic acid deposition, ${ }^{46}$ or mixture of stearic acid, N,N'-dimethylformamide (DMF), and water. ${ }^{47}$ Boiling of aluminum alloy AA60603 in water followed by immersion in stearic acid is an environmentally friendly method which avoids the use of strong acids and bases. ${ }^{48-50}$ Boiling in water produces a rough surface consisting of $\mathrm{Al}_{2} \mathrm{O}_{3} \times \mathrm{H}_{2} \mathrm{O}$ and boehmite $(\mathrm{AlOOH})$ which further react with stearic acid to form $\mathrm{Al}\left[\mathrm{CH}_{3}\left(\mathrm{CH}_{2}\right)_{16} \mathrm{COO}\right]_{3}$, as identified by FTIR and XRD. ${ }^{50}$

Recently, Wysocka et al. tested several carboxylic acids as corrosion inhibitors for Al alloy AA5754 in alkaline media, $\mathrm{pH}=11$. $^{51}$ In contrast to long-chain CAs that are usually used to achieve hydrophobicity, they considered CAs with a relatively small number of $\mathrm{C}$ atoms (up to six) and instead focused on the role of the number of carbonyl and hydroxyl groups. They found that the higher the number of carbonyl groups, the better the corrosion inhibition effect, whereas hydroxyl groups had a smaller effect. In another study aromatic CAs were used in alkaline $1 \mathrm{M} \mathrm{NaOH}$ with 3-bromo benzoic acid showing the highest efficiency of $79 \% .^{52}$

Based on the literature survey presented, it can be stated that in previous studies mainly two types of carboxylic acids were used (tetraand octadecanoic) for fabrication of modified layers on Al which were characterized by EDS, FTIR, XPS, and polarization curves in chloride solution. The aim of the present work was to address issues which have not yet been studied in much detail, and to complement the electrochemical study with surface analytical techniques and computational modelling. A two-step procedure developed by Liu et al. was followed to prepare a superhydrophobic $\mathrm{Al}$ surface. ${ }^{53}$ The first step includes alkaline etching in $0.1 \mathrm{M} \mathrm{NaOH}$ at $90^{\circ} \mathrm{C}$ to produce micro- and nano-structured roughness along with the formation of bayerite $(\beta$ $\left.\mathrm{Al}(\mathrm{OH})_{3}\right)$ microneedles, while the second step is immersion in $5 \mathrm{mM}$ ethanol solution of stearic acid and drying at room temperature. Dualscale roughness of bayerite together with low surface energy of stearic acid accounted for superhydrophobicity with $\theta$ of $167^{\circ}$ and $\alpha$ of $\sim 3^{\circ} .{ }^{53}$ This procedure was the starting point for our study which was upgraded by a systematic study of the effect of different experimental parameters on the preparation of a superhydrophobic Al surface: cooling in $\mathrm{NaOH}$, type of CA (from hexanoic to octadecanoic acid), concentration of CA (from $5 \mathrm{mM}$ to $100 \mathrm{mM}$ ) and time of immersion in CA (from $5 \mathrm{~min}$ to $1 \mathrm{~h}$ ). The morphology of layers formed upon immersion in CAs was characterized using 3D-profilometry, whereas their wettability was evaluated with water contact angle measurements. In the literature, the analysis of chemical composition of $\mathrm{Al}$ modified by CAs was mainly performed using EDS, ${ }^{37-39,42,49} \mathrm{XRD},{ }^{42,50}$ FTIR, ${ }^{42,48,49}$ and high energy XPS spectra ${ }^{47}$ or survey XPS spectra. ${ }^{41,49}$ In the present study, scanning electron microscopy combined with energy dispersive X-ray spectrometry (SEM-EDS) was applied. X-ray photoelectron spectroscopy (XPS) and time-of-flight secondary ion mass spectrometry (ToF-SIMS) were used for chemical surface analysis, following the same approach as for conversion coatings on Al alloys. ${ }^{54,55}$ In addition, adsorption of CAs was modelled with density functional theory (DFT) calculations in order to better understand the structure and self-assembly of organic films. A similar computational approach was successfully applied previously for adsorption of gallic acid on oxidized aluminum surfaces. ${ }^{56}$ Finally, the durability of the superhydrophobic surface was tested along with its self-cleaning and anti-icing properties.

\section{Experimental}

Substrate material and chemicals._Aluminum (>99.0\%) $1 \mathrm{~mm}$ thick flat sheet, distributed by GoodFellow, England, was used as substrate. Samples were cut out in a form of $1 \mathrm{~mm}$ thick flat discs with diameter $15 \mathrm{~mm}$.

For alkaline etching, $\mathrm{NaOH}$ (p.a., Labochem International) was used. For the formation of organic layers the following carboxylic acids (CAs) were used: hexanoic acid $\left(\mathrm{C}_{6} \mathrm{H}_{12} \mathrm{O}_{2}\right.$, Sigma Aldrich, 99.5\%), heptanoic acid $\left(\mathrm{C}_{7} \mathrm{H}_{14} \mathrm{O}_{2}\right.$, Fluorochem, $\left.97 \%\right)$, octanoic acid $\left(\mathrm{C}_{8} \mathrm{H}_{14} \mathrm{O}_{2}\right.$, Alfa Aesar, 98\%), nonanoic acid $\left(\mathrm{C}_{9} \mathrm{H}_{18} \mathrm{O}_{2}\right.$, Fluorochem, 95\%), decanoic acid $\left(\mathrm{C}_{10} \mathrm{H}_{20} \mathrm{O}_{2}\right.$, Alfa Aesar, 99\%), tetradecanoic acid $\left(\mathrm{C}_{14} \mathrm{H}_{28} \mathrm{O}_{2}\right.$, Fluka, $\left.98.5 \%\right)$ and octadecanoic acid $\left(\mathrm{C}_{18} \mathrm{H}_{36} \mathrm{O}_{2}\right.$, Acros Organics 97\%). Alcohol solution of carboxylic acids was prepared using ethanol (absolute for analysis EMSURE). Carboxylic acids (and their ethanol solutions) were denoted according to the number of carbon atoms: CA-6, CA-7, CA-8, CA-9, CA-10, CA-14 and CA-18, respectively.

Electrochemical measurements were performed in $0.5 \mathrm{M} \mathrm{NaCl}$, $\mathrm{pH}=5.8$ (Honeywell Fluka, 99.5\%). The following chemicals were used for the durability test: $\mathrm{NaOH}$ (p.a., Labochem International), $\mathrm{NaCl}$ (for analysis, EMSURE) and $\mathrm{HCl}$ (Sigma-Aldrich, p.a., $\geq 37 \%$ ). Solutions were prepared using Milli-Q Direct water with the resistivity of $18.2 \mathrm{M} \Omega \cdot \mathrm{cm}$ at $25^{\circ} \mathrm{C}$ (Millipore, Billerica, MA, USA).

Substrate pre-treatment.-Aluminum samples were first ground under water using SiC papers up to 2400-grit (LaboPol, Struers), 
etched in alkaline $\mathrm{NaOH}$ solution and then modified by immersion in ethanol solution of carboxylic acid. ${ }^{53}$ Briefly, $20 \mathrm{~mL} 0.1 \mathrm{M} \mathrm{NaOH}$ was heated in a flat-bottomed flask (volume $250 \mathrm{~mL}$ ) using an ISOPAD heater up to $90^{\circ} \mathrm{C}$. The aluminum samples were then immersed in $\mathrm{NaOH}$ solution and heated for 20 minutes at $90^{\circ} \mathrm{C}$. The sample was then cooled down in the same solution to room temperature and rinsed by ethanol. Samples prepared by this etching procedure are referred to as "Al". All samples were treated using this procedure unless stated otherwise, i.e., when comparing the samples with and without subsequent cooling.

Preparation of adsorbed organic layers.-Organic layers of CAs were prepared by immersion of etched $\mathrm{Al}$ samples in ethanol solution of carboxylic acid, $\mathrm{CH}_{3}\left(\mathrm{CH}_{2}\right)_{n} \mathrm{COOH}$, at room temperature. The sample was hanged in a glass vessel containing ethanol solution of carboxylic acid using a Teflon thread. After denoted immersion time, the sample was taken out, rinsed by distilled water, dried in a stream of $\mathrm{N}_{2}$ and used for further measurements. Samples prepared by etching in $\mathrm{NaOH}$ and coated by immersion in ethanol solution of CA are referred to as "CA- $x$-Al", where $x$ denotes the number of carbon atoms in the carboxylic acid.

The variable parameters were the type of carboxylic acid (CA6, CA-7, CA-8, CA-9, CA-10, CA-14 and CA-18), concentration of carboxylic acid $(5,50$ and $100 \mathrm{mM})$ and time of immersion (15 min, $30 \mathrm{~min}$ and $1 \mathrm{~h}$ ).

Characterization methods.-Electrochemical measurements.To record potentiodynamic polarization curves, a three-electrode cell (K0235 Flat Cell Kit, volume $250 \mathrm{~mL}$ Ametek, Berwyn, PA, USA) was used. Measurements were performed in $0.5 \mathrm{M} \mathrm{NaCl}$ at room temperature. A specimen ( $\mathrm{Al}$ or $\mathrm{CA}-x-\mathrm{Al})$ embedded in a Teflon holder leaving an area of $1.0 \mathrm{~cm}^{2}$ exposed to the solution, served as a working electrode. A silver/silver chloride $(\mathrm{Ag} / \mathrm{AgCl}, 0.205 \mathrm{~V}$ vs. standard hydrogen electrode) was used as a reference electrode and platinum mesh as a counter electrode. Potentials in the text refer to the $\mathrm{Ag} / \mathrm{AgCl}$ scale. Measurements were conducted using an Autolab potentiostat/galvanostat Model 204 (Utrecht, The Netherlands). Prior to measurements, the sample was allowed to stabilize under open circuit conditions for approximately $1 \mathrm{~h}$, to reach stable, quasi-steady state open circuit potential $\left(E_{\mathrm{oc}}\right)$ at the end of the stabilization period. Following stabilization, the potentiodynamic polarization curves were recorded using a $1 \mathrm{mV} / \mathrm{s}$ potential scan rate, starting $250 \mathrm{mV}$ more negative with respect to $E_{\mathrm{oc}}$, and then increased in the anodic direction. For each sample, measurements were performed at least in triplicate. Mean values with standard deviations are given in tables and a representative measurement was chosen to be presented in graphs. Corrosion potential $\left(E_{\text {corr }}\right)$ and corrosion current density $\left(j_{\text {corr }}\right)$ were obtained from an intercept between cathodic and anodic curves using Nova 1.11.2 software.

Water drop contact angle and surface roughness.-Contact angles $(\theta)$ were determined using a tensiometer Krüss DSA 20 (Krüss GmbH, Hamburg, Germany). The $\theta$ values were measured based on the image of the deionized water drop with a volume of $8-10 \mu \mathrm{L}$ on the sample surface, using Drop-shape-analysis software which enables fitting the water drop shape and precise determination of the contact angle. Each value is the average of at least three measurements made at different locations on the same sample. Mean values with standard deviations are given.

Surface roughness was measured using a contact profilometer, model Bruker DektakXT, with a $2 \mu \mathrm{m}$ tip and in a soft-touch mode with force $1 \mathrm{mN}$. The measured surface was $1 \mathrm{~mm} \times 1 \mathrm{~mm}$, the vertical analysis range $65.5 \mu \mathrm{m}$ and the vertical resolution $0.167 \mu \mathrm{m} /$ point. Measured data were analyzed with TalyMap Gold 6.2 software. Results were given as mean surface roughness $\left(S_{a}\right) \pm$ standard deviation. Each reported value of surface roughness is the average of at least three measurements made at different locations on the same sample.
Surface morphology and composition.-The morphology and composition of modified samples were characterized using the following instruments: (i) field-emission scanning electron microscope (FE-SEM) (Ultra +, Carl Zeiss, Germany), equipped with energy dispersive X-ray spectrometer (EDS) (SDD, X-Max 50, Oxford Instruments, UK); images were recorded at energy $1 \mathrm{kV}$ in LEI mode (low secondary electron image), (ii) FE-SEM (JSM 7600F, JEOL, Japan), equipped with EDS (Inca Oxford 350 EDS SDD); images were recorded at energy from 5 to $15 \mathrm{kV}$ in LEI mode, and (iii) SEM (JSM5800, JEOL, Japan), equipped with EDS (Oxford ISIS 300 EDS); images were recorded at energy $20 \mathrm{kV}$ in SEI mode (secondary electron image). Prior to analysis, the samples were sputter-coated with thin $\mathrm{Au}$ or Pt layers.

Time-of-flight secondary ion mass spectrometry (ToF-SIMS) measurements were performed using a dual beam ToF-SIMS V spectrometer (ION-TOF GmbH, Muenster, Germany). The base pressure in the analysis chamber is maintained at less than $5.0 \cdot 10^{-9}$ mbar in normal operating conditions. The total primary ion flux was less than $10^{12}$ ions $\mathrm{cm}^{-2}$ ensuring static conditions. $\mathrm{A} \mathrm{Bi}^{+}$primary ion source with a $1.2 \mathrm{pA}$ current, scanned over a $100 \times 100 \mu \mathrm{m}^{2}$ area was used as the analysis beam. 2D spectra of negatively charged ions were recorded. Each sample was analyzed at least twice on different areas of the sample. Data acquisition and processing were performed using the IonSpec software. The exact mass values of at least five known species were used for calibration of the data acquired in the negative ion mode.

X-ray Photoelectron Spectroscopy (XPS) analysis was performed using two types of instruments. The effect of type of carboxylic acid was analyzed with a Thermo Electron Escalab 250 spectrometer at CNRS Chimie-ParisTech, PSL. A monochromated Al K $\alpha$ X-ray source ( $h v 1486.6 \mathrm{eV}$ ) was used. The base pressure in the analytical chamber was maintained at $10^{-9}$ mbar. The spectrometer was calibrated using $\mathrm{Au} 4 \mathrm{f}_{7 / 2}$ at $84.1 \mathrm{eV}$. The take-off angle was $90^{\circ}$ and the analyzed area was a $500 \mu \mathrm{m}$ diameter disk. Survey spectra were recorded with a pass energy of $100 \mathrm{eV}$ at a step size of $1 \mathrm{eV}$ and high resolution spectra of the $\mathrm{C} 1 \mathrm{~s}, \mathrm{O} 1 \mathrm{~s}$, and $\mathrm{Al} 2 \mathrm{p}$ core level regions were recorded with a pass energy of $20 \mathrm{eV}$ at a step size of $0.1 \mathrm{eV}$. Curve fitting of the spectra was performed with the Thermo Electron software Avantage, using an iterative Shirley-type background subtraction. Symmetrical peaks were used. The values of the photoionization cross-sections $\left(\sigma_{X}\right)$ at $1486.6 \mathrm{eV}$ were taken from Scofield, ${ }^{57}$ and the inelastic mean free paths $\left(\lambda_{X}^{Y}\right)$ were calculated by the TPP2M formula. ${ }^{58}$

The effect of etching time was analyzed with a PHI-TFA XPS spectrometer (Physical Electronic Inc.) at Jožef Stefan Institute, Department of Surface Engineering and Optoelectronics. The vacuum during the XPS analysis was in the range of $10^{-9}$ mbar. The analyzed area was $400 \mu \mathrm{m}$ in diameter and the analyzed depth about $3-5 \mathrm{~nm}$. $\mathrm{X}$-rays were provided from a monochromatic $\mathrm{Al}$ source at photon energy of $h v 1486.6 \mathrm{eV}$. Survey and high-energy resolution spectra were recorded. The high-energy resolution spectra were acquired with an energy analyser operating at a resolution of ca. $0.6 \mathrm{eV}$ and a pass energy of $29.3 \mathrm{eV}$. XPS spectra were analyzed by Multipak software, version 8.0 (Physical Electronics Inc.). During data processing the spectra were corrected by setting the $\mathrm{C} 1 \mathrm{~s}$ peak to binding energy $\left(E_{\mathrm{b}}\right)$ $284.8 \mathrm{eV}$, which is characteristic of $\mathrm{C}-\mathrm{C} / \mathrm{C}-\mathrm{H}$ bonds. The accuracy of the binding energies was $\pm 0.3 \mathrm{eV}$. Survey XPS spectra were used to deduce the elemental composition of the coatings based on the total intensity of particular element peaks and using values of photoionization cross sections $\left(\mathrm{C} 1 \mathrm{~s}=0.857, \mathrm{O} 1 \mathrm{~s}=2.51, \mathrm{Al} 2 \mathrm{p}_{3 / 2}=0.332\right)$.

Computational details.-Calculations were performed in the framework of density-functional theory (DFT) using the generalized gradient approximation of Perdew-Burke-Ernzerhof (PBE) $)^{59}$ and plane-wave basis set as implemented in the Quantum ESPRESSO ${ }^{60}$ and VASP ${ }^{61,62}$ packages. To better describe lateral intermolecular interactions between carboxylic acids, we used the empirical dispersion correction of Grimme, ${ }^{63}$ known as D2. However, given that on oxidized $\mathrm{Al}$ substrates $\mathrm{Al}$ is in the +3 oxidation state and hence devoid 
$\mathrm{OH} / \mathrm{Al}_{x} \mathrm{O} / \mathrm{Al}(111)$

$7.1 \mathrm{OH} / \mathrm{nm}^{2}$

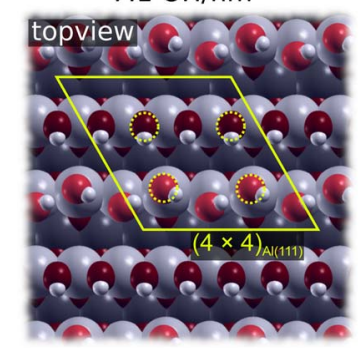

sideview

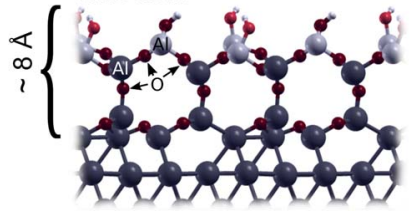

$\mathrm{AlOOH} / \mathrm{Al}_{2} \mathrm{O}_{3} / \mathrm{Al}(111)$

$14.4 \mathrm{OH} / \mathrm{nm}^{2}$

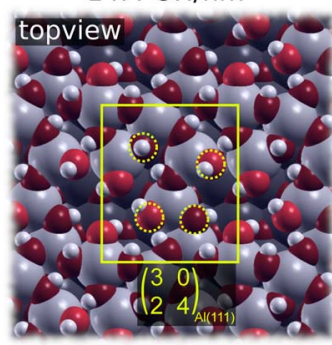

sideview

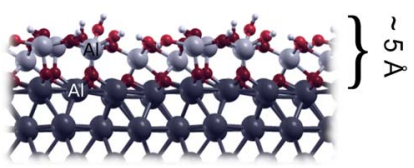

Figure 1. Top- and side-views of the two models used in this study: $\mathrm{OH} / \mathrm{Al}_{\mathrm{x}} \mathrm{O} / \mathrm{Al}(111)$ [left] and $\mathrm{AlOOH} / \mathrm{Al}_{2} \mathrm{O}_{3} / \mathrm{Al}(111)$ [right]. The corresponding supercells are outlined; with respect to $\mathrm{Al}(111)$ support these are $(4 \times 4)$ for the $\mathrm{OH} / \mathrm{Al}_{\mathrm{x}} \mathrm{O} / \mathrm{Al}(111)$ model and $\left(\begin{array}{ll}3 & 0 \\ 2 & 4\end{array}\right)$ for the $\mathrm{AlOOH} / \mathrm{Al}_{2} \mathrm{O}_{3} / \mathrm{Al}(111)$ model. Note that atoms are drawn on the basis of atomic and not ionic radii: $\mathrm{Al}$ (bigger gray spheres), $\mathrm{O}$ (smaller red spheres), and $\mathrm{H}$ (smallest white spheres). The surface $\mathrm{OH}$ groups replaced by carboxylate species are indicated with dashed circles. Terminal $\mathrm{OH}$ groups are shown in a lighter red color, while bridging $\mathrm{OH}$ groups are shaded in a darker red color. In the side-views the approximate thickness of both hydroxylated oxide films is also indicated.

of valence electrons, we set the $C_{6}$ coefficient of $\mathrm{Al}$ to zero. The results obtained by this scheme will be referred to by the PBE- $\mathrm{D}_{0}$ denotation, where the subscript ' 0 ' is used as mnemonic to recall that $C_{6}{ }^{\mathrm{Al}}=0$.

VASP calculations were performed with projector-augmented wave (PAW) potentials ${ }^{64,65}$ with an energy cutoff of $520 \mathrm{eV}$. Geometry optimizations performed in this work were considered converged when the forces were smaller than $0.02 \mathrm{eV} / \AA$.

Quantum ESPRESSO calculations were performed with the PWscf code. We used ultrasoft pseudopotentials. ${ }^{66,67}$ Kohn-Sham orbitals were expanded in a plane-wave basis set up to a kinetic energy cutoff of 35 Ry (280 Ry for the charge-density cutoff). Brillouin zone integrations were performed with the special point technique using a Methfessel-Paxton smearing of 0.03 Ry.

For both sets of calculations, a dipole correction was applied along the direction normal to the surface when dealing with surfaces. Molecular graphics were produced by XCRYSDEN graphical package. ${ }^{68}$

Models of hydroxylated oxidized aluminum surfaces.-Two models of the hydroxylated oxidized aluminum surface, designated as $\mathrm{OH} / \mathrm{Al}_{\mathrm{x}} \mathrm{O} / \mathrm{Al}(111)$ and $\mathrm{AlOOH} / \mathrm{Al}_{2} \mathrm{O}_{3} / \mathrm{Al}(111)$, were utilized in this study. The former, $\mathrm{OH} / \mathrm{Al}_{\mathrm{x}} \mathrm{O} / \mathrm{Al}(111)$, is taken from our previous publication and is described in greater detail therein. ${ }^{69}$ It is based on oxidizing the $\mathrm{Al}(111)$ surface with an equivalent of $2 \mathrm{ML}$ of oxygen atoms along the lines followed by Lanthony et al. ${ }^{70}$ The so obtained ultrathin oxide film is approximately $5 \AA$ thick. The topmost oxide layer is then fully hydroxylated. The surface $\mathrm{OH}$ density corresponding to full coverage on this model of the film is $7.1 \mathrm{OH} \mathrm{nm}^{-2}$, which is slightly lower than is typical for aluminum oxide surfaces. ${ }^{71}$ In the current study, the surface model is built from 6 layers of $\mathrm{Al}(111)$. All calculations were performed with a $(4 \times 4)$ supercell of $\mathrm{Al}(111)$ and a $3 \times 3 \times 1$ k-point grid, employing the previously calculated Al bulk lattice parameter of $4.04 \AA$; these calculations were performed with Quantum ESPRESSO. The top- and side-views of this film are shown on the left side of Fig. 1.

The second model, designated as $\mathrm{AlOOH} / \mathrm{Al}_{2} \mathrm{O}_{3} / \mathrm{Al}(111)$, is taken from another previous publication of ours. ${ }^{72}$ For the bulk materials, the bulk lattice constants are $a=4.06 \AA$ for $\mathrm{Al}$ and $a=9.78 \AA, b$
$=8.32 \AA$ and $c=13.56 \AA$ for $\gamma-\mathrm{Al}_{2} \mathrm{O}_{3}$, in good agreement with experimental values. The corresponding surface model is built from a $\left(\begin{array}{ll}3 & 0 \\ 2 & 4\end{array}\right)$ supercell of $\mathrm{Al}(111)$; the slab consists of 5 metallic aluminum (111) layers that is supporting a $5 \AA$ thick hydroxylated aluminum oxide film; the model is shown on the right side of Fig. 1. These calculations were performed with VASP using a $3 \times 3 \times 1$ k-point grid. The oxide film has a stoichiometry of $\mathrm{Al}_{2} \mathrm{O}_{2.57}$ and exhibits a hydroxyl density of $14.4 \mathrm{OH} \mathrm{nm}{ }^{-2} \cdot{ }^{71}$ It is composed of $\gamma-\mathrm{Al}_{2} \mathrm{O}_{3}(111)$. This face is polar, with alternation of $\mathrm{O}$ and $\mathrm{Al}$ planes. The $\mathrm{Al}$ planes contain Al with either octahedral or tetrahedral coordination. We showed in our previous work that the oxide layer has an Al octahedral plane at the interface with the metal. Two types of $\mathrm{OH}$ groups are found: terminal $\mathrm{OH}$ groups, bound to a single $\mathrm{Al}$ ion ( $40 \%$ of the $\mathrm{OH}$ groups), and bridging $\mathrm{OH}$ groups, bonded to two $\mathrm{Al}$ ions (60\% of the $\mathrm{OH}$ groups). The different types of $\mathrm{OH}$ groups are also indicated in Fig. 1.

Durability, self-cleaning, and melting delay tests.-Durability tests were performed by immersion of $\mathrm{Al}$ and $\mathrm{CA}-x-\mathrm{Al}$ samples in different solutions and measuring the contact angle of water drop at the surface at different time intervals $(0,2,4,24$ and $48 \mathrm{~h})$. The test was performed in the following solutions: $3.5 \mathrm{wt} \% \mathrm{NaCl}(\mathrm{pH}=5.8)$, $\mathrm{NaOH}(\mathrm{pH}=11)$ and $\mathrm{HCl}(\mathrm{pH}=4)$.

Self-cleaning ability of the surface was demonstrated by spreading carbon particles at the surface and adding water droplets to cause the removal of carbon contaminant particles. The images were taken using a digital camera.

The anti-icing properties were studied on ground $\mathrm{Al}$ and etched Al modified with carboxylic acid using the melting delay time test. The test was performed with water droplets of $8 \mu \mathrm{L}\left(T_{\text {water }}=25^{\circ} \mathrm{C}\right)$, which were gently placed on the horizontal aluminum substrate at room temperature. The samples were then put into the freezer $(T=$ $-20^{\circ} \mathrm{C}$ ) for at least 30 minutes to fully freeze the drops. After the samples were taken out, they were left at room temperature to melt. The melting delay times were evaluated by recording the melting times for drops on non-treated and treated aluminum.

\section{Results and Discussion}

Morphology and composition of etched aluminum.-First, the ground and etched surface will be compared in order to show the importance of surface preparation for obtaining a superhydrophobic surface. SEM images, 3D profiles, and water contact angles of ground $\mathrm{Al}$ and $\mathrm{Al}$ etched in $0.1 \mathrm{M} \mathrm{NaOH}$ are presented in Fig. 2. Ground $\mathrm{Al}$ shows a flat surface but with the presence of various defects related to grinding with $\mathrm{SiC}$ papers up to 2400-grit (Fig. 2a). Based on the 3D topographic profile the mean surface roughness, $S_{\mathrm{a}}$, of $0.29 \pm 0.01$ $\mu \mathrm{m}$ was determined (Fig. 2b). Ground $\mathrm{Al}$ surface exhibited the water contact angle of $62^{\circ}$. After etching in $\mathrm{NaOH}$, the surface properties changed: instead of being flat, the surface was hierarchically rough, showing different patterns from platelets to cones (Fig. 2c). Roughness increased from $0.29 \pm 0.01 \mu \mathrm{m}$ to $8.07 \pm 0.65 \mu \mathrm{m}$ (Fig. $2 \mathrm{~d}$ ); at the same time, the wettability of the surface changed from hydrophilic to superhydrophilic, i.e., from $\theta=62^{\circ}$ to $\theta<5^{\circ}$. Images of water drops at the surface of ground and etched $\mathrm{Al}$ will be presented later in the text. The change in wettability confirms the behavior according to the Wenzel model which predicts that for hydrophilic surfaces wettability increases with increasing surface roughness. ${ }^{2}$

Morphology of $\mathrm{Al}$ surfaces produced by etching in $\mathrm{NaOH}$ was further investigated in more detail. Etching resulted in the formation of a rough, structured surface layer (Fig. 3a). The bottom layer exhibited platelet-like morphology (Fig. 3b); it is composed of either $\mathrm{Al}$ oxide or, more likely, hydroxide or oxohydroxide (32.7 at.\% $\mathrm{Al}$ and 67.3 at.\% O), as evidenced by EDS analysis. The $\mathrm{Al} / \mathrm{O}$ ratio is 0.48 , which is close to the stoichiometric values of 0.5 in $\mathrm{AlOOH}$ (in $\mathrm{Al}(\mathrm{OH})_{3}$ this value is 0.33 and in $\mathrm{Al}_{2} \mathrm{O}_{3}$ 0.67). Above this plateletlike layer, micrometer-sized cones (10-20-micrometers in length and few micrometers in diameter) formed irregularly throughout the 

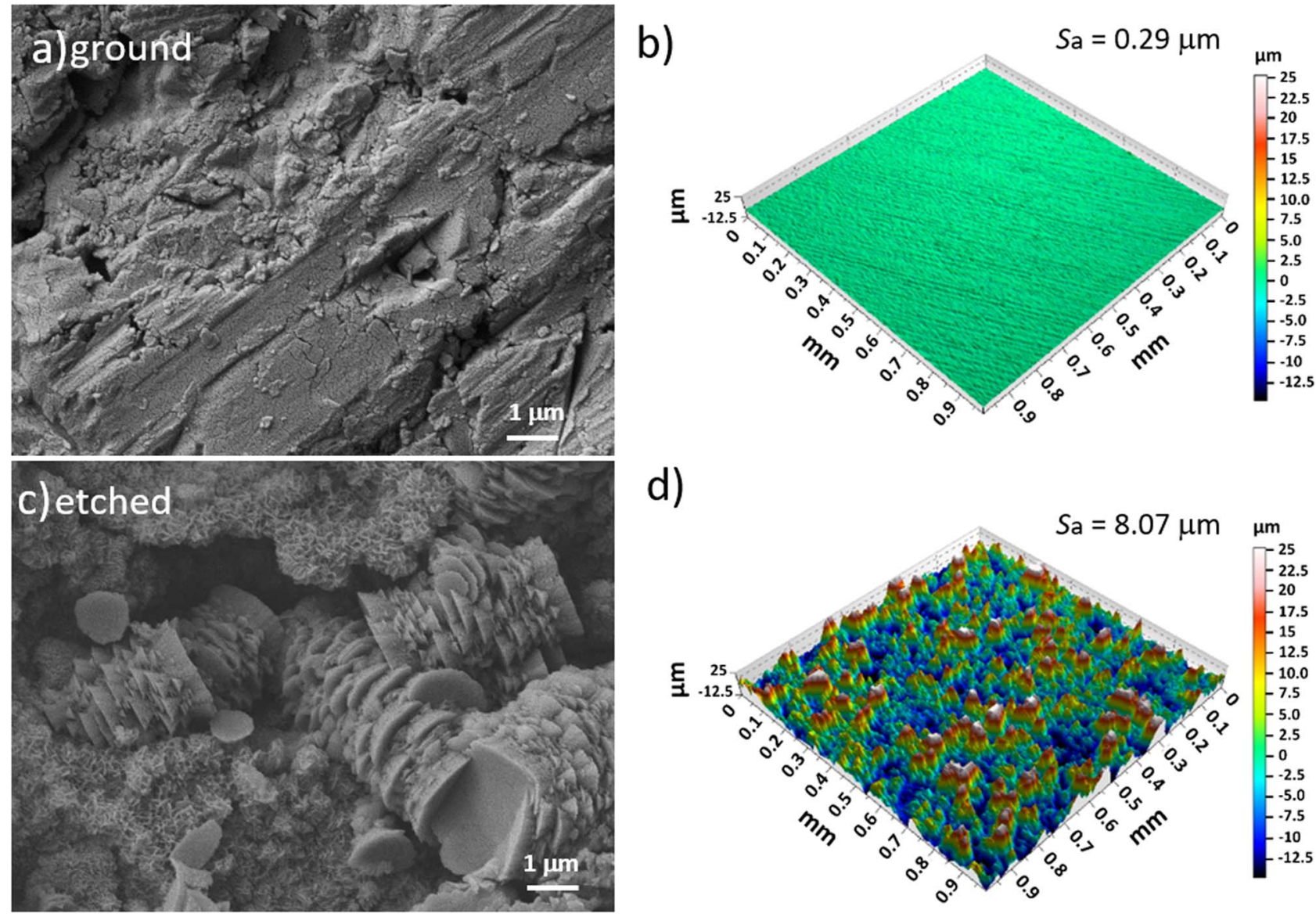

d)

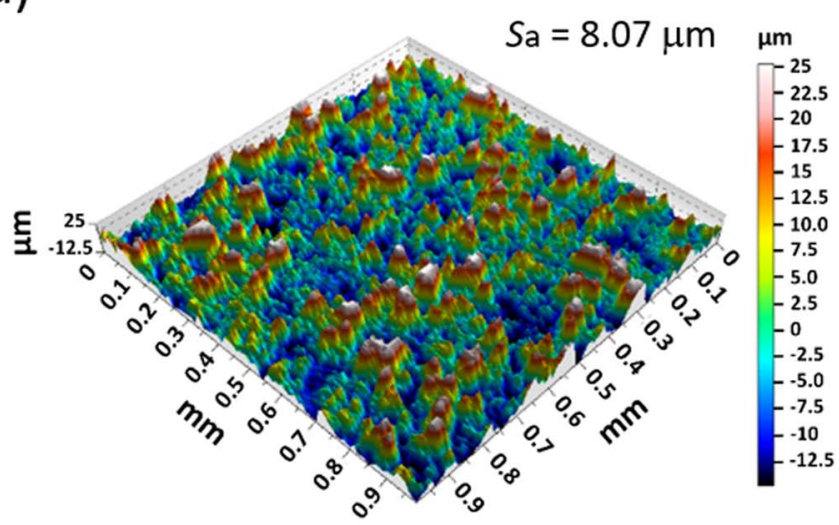

Figure 2. SEM images and 3-D topography profiles recorded on the surface of (a, b) ground $\mathrm{Al}$ and (c, d) $\mathrm{Al}$ etched for 20 minutes in $0.1 \mathrm{M} \mathrm{NaOH}$ at $90^{\circ} \mathrm{C}$ and cooled to room temperature. (b, d) Mean values of surface roughness $S_{\mathrm{a}}$ are given. The coloring of roughness is according to the scale on the right (from $-12.5 \mu \mathrm{m}$ to $22 \mu \mathrm{m})$. SEM images were recorded at energy $5 \mathrm{kV}$ in SEI mode.
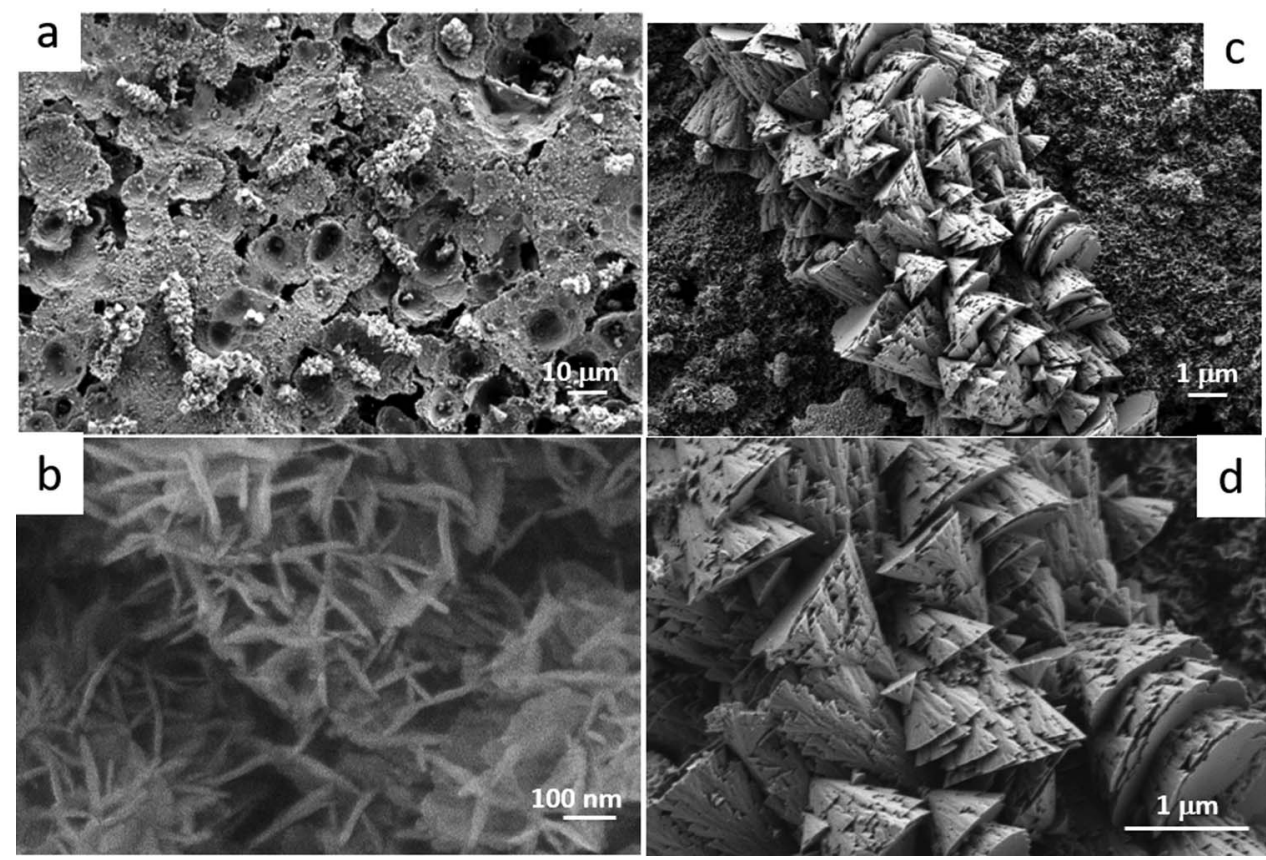

Figure 3. FE-SEM images of $\mathrm{Al}$ after etching for $20 \mathrm{~min}$ in $0.1 \mathrm{M} \mathrm{NaOH}$ at $90^{\circ} \mathrm{C}$ and cooled to room temperature: (a) hierarchically rough structure showing platelet-like bottom layer and micrometer-sized cones, (b) high resolution image of platelet-like bottom layer, (c,d) high resolution images of cones. SEM images were recorded at energy $(\mathrm{a}, \mathrm{b}) 10 \mathrm{kV}$ and $(\mathrm{c}, \mathrm{d}) 1 \mathrm{kV}$ in SEI mode. 
surface (Fig. 3c). Cones did not completely cover the surface layer thus forming an "open structure" above a bottom, platelet-like hydroxide layer. SEM image of cones at higher magnification proved that each cone was nano-structured, showing terraced, pyramidal-like structure (Fig. 3d). EDS analysis confirmed that the cones also consisted of $\mathrm{Al}$ hydroxide but with somewhat higher oxygen content (34.5 at.\% Al and 65.4 at.\% O) giving the $\mathrm{Al} / \mathrm{O}$ ratio of 0.53 . Hierarchically structured $\mathrm{Al}$ hydroxide was superhydrophilic with water contact angle $(\theta)$ below $10^{\circ}$.

The mechanism of formation of Al-hydroxide includes fast etching of $\mathrm{Al}$ by $\mathrm{OH}^{-}$ions from solution and evolution of hydrogen bubbles according to: ${ }^{53}$

$$
2 \mathrm{Al}+2 \mathrm{OH}^{-}+6 \mathrm{H}_{2} \mathrm{O} \rightarrow 2 \mathrm{Al}(\mathrm{OH})_{4}^{-}+3 \mathrm{H}_{2}
$$

Fast etching is followed by the reaction of hydroxide ions with $\mathrm{CO}_{2}$ from air and formation of $\beta-\mathrm{Al}(\mathrm{OH})_{3}$ :

$$
2 \mathrm{Al}(\mathrm{OH})_{4}^{-}+\mathrm{CO}_{2} \rightarrow 2 \beta \mathrm{Al}(\mathrm{OH})_{3}+\mathrm{CO}_{3}^{2-}+\mathrm{H}_{2} \mathrm{O}
$$

As the concentration of available $\mathrm{CO}_{2}$ is low, ${ }^{53}$ the kinetics is slow and the mechanism of hydroxide formation changes from initial heterogeneous nucleation throughout the surface (platelet-like morphology) to anisotropic growth of $\beta-\mathrm{Al}(\mathrm{OH})_{3}$ nuclei which results in cone formation. This process proceeds very slowly, presumably during cooling, as will be shown below.

The composition of the etched layer was further analyzed using XPS and ToF-SIMS. XPS spectra recorded on the etched Al surface are shown in Fig. 4 (spectrum denoted as Al). The survey spectrum shows that the main elements at the surface are aluminum, oxygen and
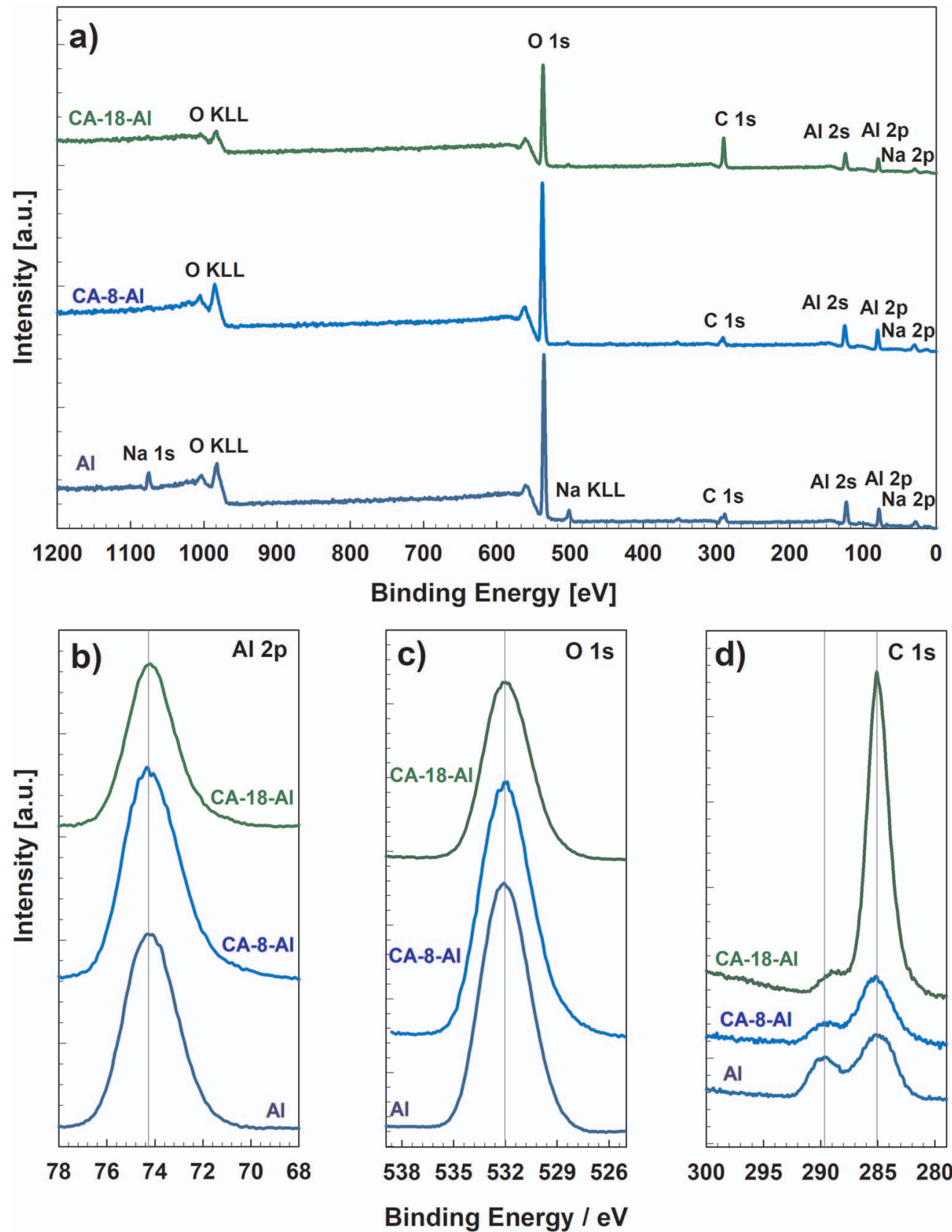

Figure 4. (a) XPS survey spectra of $\mathrm{Al}$ after etching for 20 minutes in $0.1 \mathrm{M} \mathrm{NaOH}$ at $90^{\circ} \mathrm{C}$, cooled to room temperature (curve labelled as $\mathrm{Al}$ ) and after subsequent immersion for 30 minutes in $5 \mathrm{mM}$ ethanol solution of octanoic (CA-8-Al) and octadecanoic acid (CA-18-Al). High energy resolution spectra are also given: (b) $\mathrm{Al} \mathrm{2p}$, (c) $\mathrm{O} 1 \mathrm{~s}$ and (d) $\mathrm{C} 1 \mathrm{~s}$. The position of the spectra was corrected according to the binding energy of C 1s peak at $285.0 \mathrm{eV}$. Spectra were not normalized regarding the intensity scale. 
a)
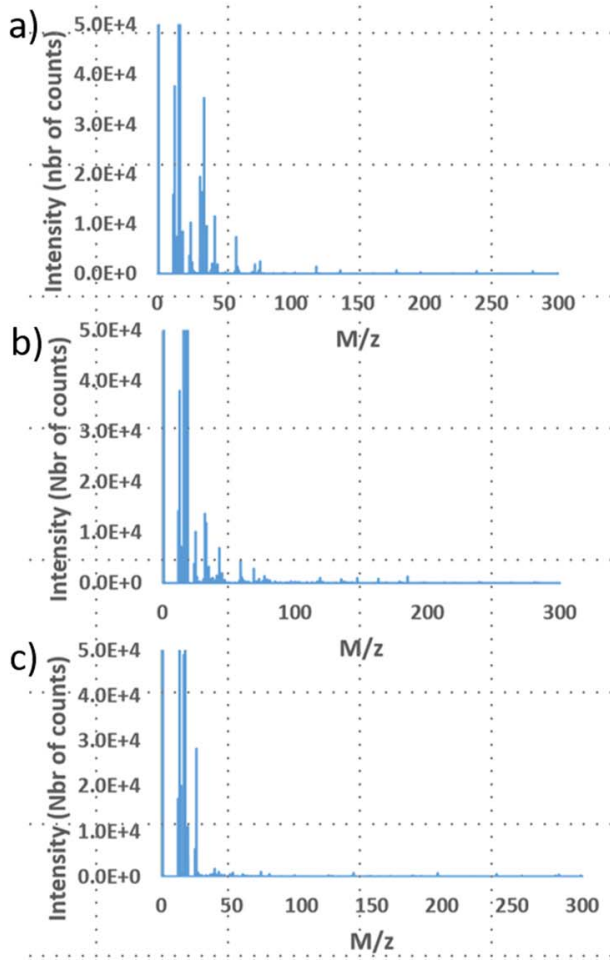
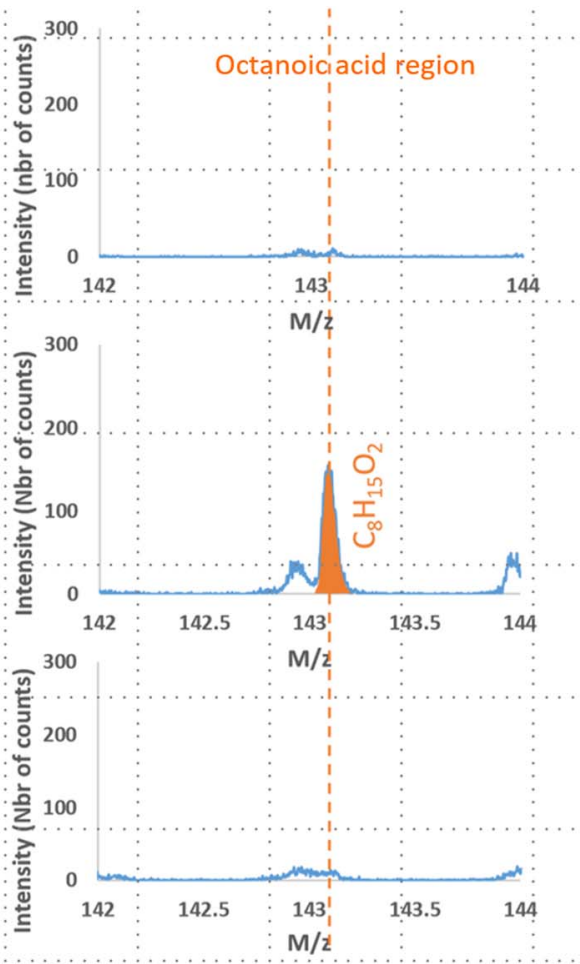

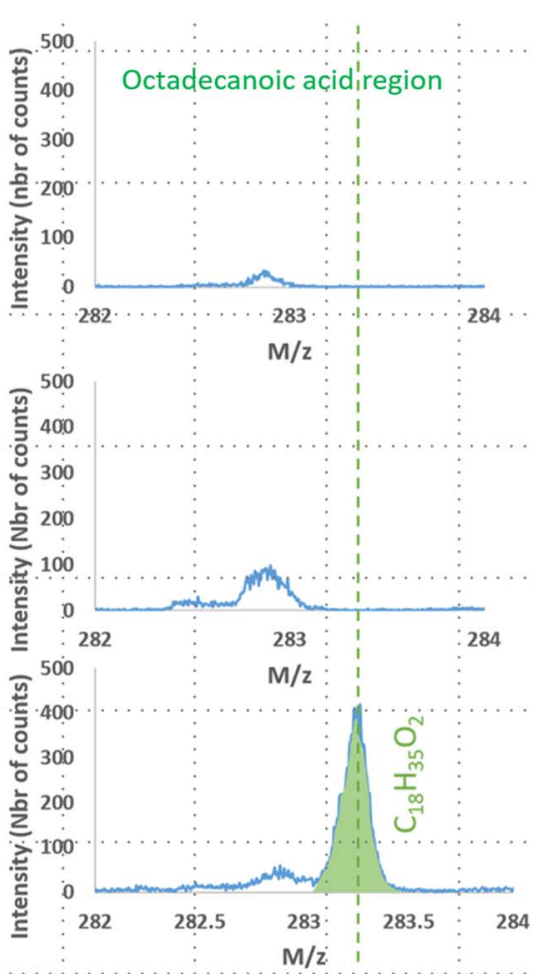

Figure 5. ToF-SIMS spectra for (a) $\mathrm{Al}$ after etching for 20 minutes in $0.1 \mathrm{M} \mathrm{NaOH}$ at $90^{\circ} \mathrm{C}$ and cooled to room temperature, and $\mathrm{Al}$ after etching in $0.1 \mathrm{M} \mathrm{NaOH}$ and immersed for 30 minutes in $5 \mathrm{mM}$ ethanol solution of (b) octanoic acid (CA-8) and (c) octadecanoic acid (CA-18).

carbon (Fig. 4a); a small concentration of sodium was also detected. The $\mathrm{Al} 2 \mathrm{p}$ core level spectrum presents a peak centered at $74.2 \mathrm{eV}$ (Fig. 4b) and is assigned to aluminum hydroxide species. ${ }^{73}$ The $\mathrm{O} 1 \mathrm{~s}$ peak centered at $532 \mathrm{eV}$ is assigned to hydroxide species (Fig. 4c). The C 1s core level spectrum (Fig. 4d) can be decomposed into two components assigned to carbon bonded to carbon and hydrogen $(\mathbf{C}-\mathrm{C}$ and $\mathbf{C}-\mathrm{H}$ ) at $285 \mathrm{eV}$ and carbon making one double bond and one single bond with oxygen $(\mathrm{O}=\mathbf{C}-\mathrm{O})$ in the carboxyl group at $289.3 \mathrm{eV} .^{74}$ The presence of carbon is associated with an adventitious contamination layer.

A ToF-SIMS spectrum recorded on etched $\mathrm{Al}$ is taken as a reference for further analysis (Fig. 5a). For samples etched in sodium hydroxide and not exposed to carboxylic acids afterwards, the characteristic peaks associated with octanoic acid at mass to charge ratio $\mathrm{m} / \mathrm{z}=143$, and with stearic acid at $\mathrm{m} / \mathrm{z}=283$ are not detected.

\section{Morphology and composition of etched aluminum immersed in} ethanol solution of $\boldsymbol{C A}$.- After immersion of the etched Al sample in ethanol solution of CA, no significant changes can be observed using SEM and FE-SEM. Examples of SEM images recorded for etched $\mathrm{Al}$, and etched $\mathrm{Al}$ immersed in ethanol solution of carboxylic acids (CA-7-Al, CA-10-Al and CA-18-Al) are shown in Fig. SI-1. Surfaces therefore retained their micro- and nano-features also after immersion in ethanol solution of CAs. Composition determined by EDS analysis at the cones (30.9 at.\% $\mathrm{Al}$ and 69.1 at.\% O) was similar to that measured on etched $\mathrm{Al}$ corresponding to $\mathrm{Al}$ hydroxide. The presence of organic species originating from immersion in CAs could not be identified due to the fact that the layer formed was too thin to be detected by EDS for which the sampling depth is in the micrometer range. However, the presence of an organic layer can be indirectly confirmed by the gradual change in wettability as the length of the alkyl chain of CA increases, i.e., the surfaces of CA-7-Al, CA-8-Al, CA-9-Al and CA-10-Al were hydrophilic, that of CA-14-Al was hydrophobic, and CA-18-Al was superhydrophobic (Fig. SI-1).
More appropriate techniques to determine the composition of the thin surface layers are XPS and ToF-SIMS. XPS spectra recorded on the $\mathrm{Al}$ etched surface exposed to CA- 8 and CA-18 are shown in Fig. 4 (spectra denoted CA-8-Al and CA-18-Al), respectively. Survey spectra (Fig. 4a) show that the main elements at the surface are aluminum, oxygen and carbon. Compared to etched $\mathrm{Al}$ (spectrum denoted $\mathrm{Al}$ ), however, the spectrum recorded after exposure to CA-8 and, especially, to CA-18, exhibited a significantly larger concentration of carbon, confirming that organic acids were adsorbed on the surface.

The $\mathrm{Al} 2 \mathrm{p}$ and $\mathrm{O} 1 \mathrm{~s}$ core level spectra of etched aluminum immersed in CA-8 and CA-18, present peaks centered at $74.2 \mathrm{eV}$ and $532 \mathrm{eV}$, respectively, similar to etched Al (Figs. 4b and 4c). These peaks are associated with aluminum hydroxide species as for the reference sample of etched Al. The C 1s core level spectrum (Fig. 4d) was decomposed into two components assigned to aliphatic carbon $(\underline{\mathbf{C}}-\mathrm{C}$ and $\mathbf{C}-\mathrm{H})$ at $285 \mathrm{eV}$ and carbon with a double and a single bond with oxygen $(\mathrm{O}=\mathbf{C}-\mathrm{O})$ in carboxyl groups at $289.3 \mathrm{eV}$. On the $\mathrm{Al}$ etched surface a small contribution at higher binding energy $(290.2 \mathrm{eV})$ is attributed to carbonate species. In the presence of CA-18 the peak related to aliphatic carbon at $285 \mathrm{eV}$ increased considerably, which seems reasonable due to its long aliphatic tail.

Table I compares the $(\mathbf{C}-\mathrm{C}$ and $\underline{\mathbf{C}}-\mathrm{H}) / \mathrm{O}=\underline{\mathbf{C}}-\mathrm{O}$ atomic ratio obtained on surfaces exposed to octanoic and octadecanoic acids to the stoichiometric ratio. For octanoic acid the experimental $(\mathbf{C}-\mathrm{C}$ and C-H)/O-C $=\mathrm{O}$ atomic ratio was considerably lower than the stoichiometric value of 7 meaning that carbonaceous species at the surface are not related only to octanoic acid but probably to a mixture of octanoic acid and carbonaceous contamination. Contamination by $\mathbf{C}-\mathrm{C}$ and $\mathrm{O}-$ $\mathbf{C}=\mathrm{O}$ species was observed on the reference sample surface as well. In contrast, after exposure to octadecanoic acid the experimental ratio is in good agreement with the stoichiometry of the CA-18 molecule and suggests that carbonaceous contamination was replaced by adsorption of octadecanoic acid.

Assuming a simple model consisting of an aluminum hydroxylated layer covered with octanoic and octadecanoic acid molecules bounded 
Table I. The (C-C and $\mathrm{C}-\mathrm{H}) / \mathrm{O}-\mathrm{C}=\mathrm{O}$ atomic ratio obtained on etched $\mathrm{Al}$ for 20 minutes in $0.1 \mathrm{M} \mathrm{NaOH}$ and then immersed for 30 minutes in $5 \mathrm{mM}$ ethanol solution of octanoic and octadecanoic acid, respectively (labelled as CA-8-Al and CA-18-AI), as deduced from XPS spectra in Fig. 4. Values for stoichiometric ratios in octanoic and octadecanoic acids are also given.

$(\underline{\mathrm{C}}-\mathrm{C}$ and $\underline{\mathrm{C}}-\mathrm{H}) / \mathrm{O}-\underline{\mathrm{C}}=\mathrm{O}$ atomic ratio

\begin{tabular}{lcc}
\cline { 2 - 3 } Sample & experimental & stoichiometric \\
\hline CA-8-Al & 3.7 & 7 \\
CA-18-Al & 17.4 & 17
\end{tabular}

perpendicularly to the surface (length of the octanoic acid and octadecanoic acid molecules are $1.1 \mathrm{~nm}$ and $2.3 \mathrm{~nm}$, respectively), the coverage of the surface can be estimated taking into account the intensities of aluminum and carbon peaks: ${ }^{75}$

$$
\begin{aligned}
& I_{\mathrm{Al}}^{\mathrm{Al}(\mathrm{OH})_{3}}=\gamma k \sigma_{\mathrm{Al}} \lambda_{\mathrm{Al}}^{\mathrm{Al}(\mathrm{OH})_{3}} D_{\mathrm{Al}}^{\mathrm{Al}(\mathrm{OH})_{3}} T_{\mathrm{Al}} \exp \left(-\frac{d}{\lambda_{\mathrm{Al}}^{\mathrm{org}}}\right) \\
& +(1-\gamma) k \sigma_{\mathrm{Al}} \lambda_{\mathrm{Al}}^{\mathrm{Al}(\mathrm{OH})_{3}} D_{\mathrm{Al}}^{\mathrm{Al}(\mathrm{OH})_{3}} T_{\mathrm{Al}} \\
& I_{\mathrm{C}}^{\mathrm{org}}=\gamma k \sigma_{\mathrm{C}}^{\mathrm{org}} \lambda_{\mathrm{C}}^{\mathrm{org}} D_{\mathrm{C}}^{\mathrm{org}} T_{\mathrm{C}}\left(1-\exp \left(-\frac{d}{\lambda_{\mathrm{C}}^{\mathrm{org}}}\right)\right)
\end{aligned}
$$

with $I_{X}^{Y}$ the intensity of photoelectrons emitted by the element $X$ (in the considered core level) in the substance $Y, k$ a constant characteristic of the spectrometer, $\sigma_{X}$ the photoionization cross-section of the core level of the element $X, \lambda_{X}^{Y}$ the inelastic mean free path of photoelectrons emitted by the core level of the element $X$ in the matrix $Y, D_{X}^{Y}$ the density of the element $X$ in the matrix $Y, T_{X}$ the transmission function of the core level of the element $X, d$ the thickness of the organic layer, and $\gamma$ the coverage. The volume number density of $\mathrm{C}$ atoms in the organic film $\left(D_{\mathrm{C}}^{\text {org }}\right)$ was estimated from DFT calculations by assuming a perpendicular orientation of CA molecules and a full monolayer coverage of $4.72 \mathrm{~nm}^{-2}$; the resulting densities are $0.065 \mathrm{~mol} \mathrm{~cm}^{-3}$ and $0.066 \mathrm{~mol} \mathrm{~cm} \mathrm{c}^{-3}$ for CA-8 and CA-18, respectively. By assuming that CA molecules adsorb upright to the surface, the coverage is estimated to about $65 \%$ after immersion in octanoic acid and $100 \%$ after immersion in octadecanoic acid. The octanoic acid coverage is overestimated because of the presence of carbonaceous contamination at the surface.

ToF-SIMS spectra recorded on an alkaline etched $\mathrm{Al}$ and immersed in CA- 8 and CA-18 are shown in Figs. $5 \mathrm{~b}$ and $5 \mathrm{c}$. In contrast to the reference sample of etched aluminum (Fig. 5a), the samples exposed to carboxylic acids show characteristic peaks associated with octanoic acid $\left(\mathrm{m} / \mathrm{z}=143\right.$ assigned to $\mathrm{C}_{8} \mathrm{H}_{15} \mathrm{O}_{2}{ }^{-}$ion $)$and stearic acid $(\mathrm{m} / \mathrm{z}=$ 283 assigned to $\mathrm{C}_{18} \mathrm{H}_{35} \mathrm{O}_{2}{ }^{-}$ion). Ions associated with short aliphatic chains, such as $\mathrm{CH}_{2}{ }^{-}, \mathrm{CH}_{3}{ }^{-}$, and $\mathrm{C}_{2} \mathrm{H}_{4}{ }^{-}$, are also identified in the mass spectra (not shown). They are assigned to the contamination layer present on the etched $\mathrm{Al}$ reference sample after storage and transfer to the spectrometer. Thus, ToF-SIMS analysis confirms that after immersion in octanoic and octadecanoic acid, a layer of the respective acid is formed at the surface of etched Al.

Effect of etching parameters on the properties of aluminum prior and after immersion in ethanol solution of CA.-The effects of different parameters of etching and immersion in ethanol CA solution on the morphology and composition of the organic layers formed were investigated, in particular: (i) surface preparation, i.e., grinding and etching, prior to immersion in CA solution, (ii) cooling step following etching in $\mathrm{NaOH}$, (iii) etching time in $\mathrm{NaOH}$, (iv) concentration of CA solution, and (v) immersion time in CA solution. First, the ground and etched surface will be compared in order to show the importance of surface preparation for obtaining a superhydrophobic surface. SEM images and 3D profiles confirm that the morphological and topographical properties of ground and alkaline etched $\mathrm{Al}$ differ considerably (Fig. 2), as well as their wettability properties. In order

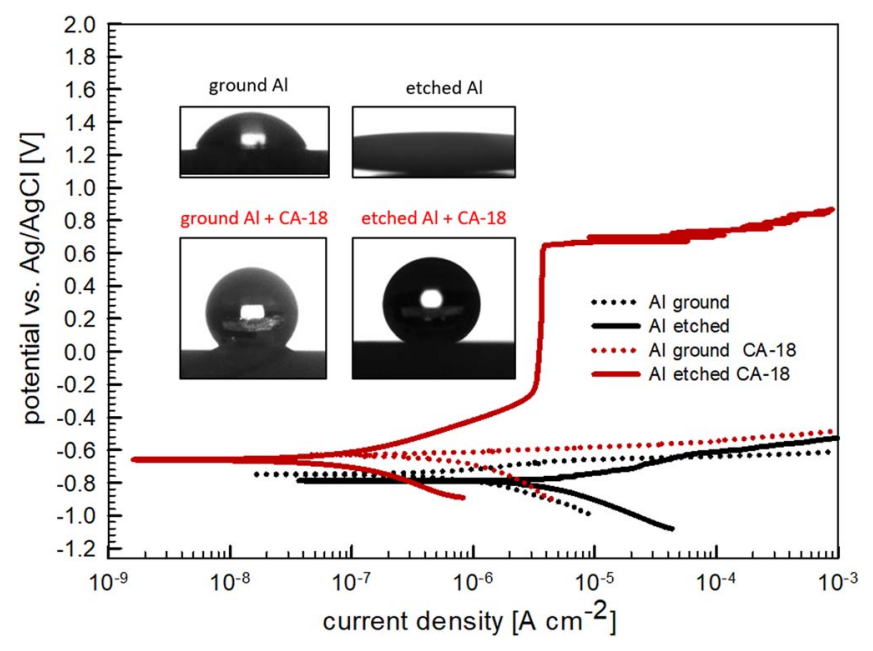

Figure 6. Potentiodynamic polarization curves recorded in $0.5 \mathrm{M} \mathrm{NaCl}$ for ground $\mathrm{Al}, \mathrm{Al}$ etched for 20 minutes in $0.1 \mathrm{M} \mathrm{NaOH}$ at $90^{\circ} \mathrm{C}$ and cooled to room temperature, and ground and etched $\mathrm{Al}$ immersed in $5 \mathrm{mM}$ ethanol solution of octadecanoic acid (CA-18) for 30 minutes. Scan rate was $1 \mathrm{mV} / \mathrm{s}$. Images of water drop at the surface are given in the inset.

to check how surface preparation affects the subsequent adsorption of organic acid, both ground and etched Al were immersed in CA-18 solution for 30 minutes. Water contact angles were then measured and potentiodynamic curves were recorded in $0.5 \mathrm{M} \mathrm{NaCl}$ (Fig. 6). Prior to immersion in CA-18 solution, $\theta$ was $62^{\circ} \pm 1^{\circ}$ and $<5^{\circ}$ for ground and etched $\mathrm{Al}$, respectively, whereas after immersion it increased to $138^{\circ} \pm 1^{\circ}$ and $155^{\circ} \pm 1^{\circ}$. Therefore, the ground surface became hydrophobic and the etched surface superhydrophobic. The images of water drops on ground and etched surface treated by CA-18 clearly show the difference in wettability of the two surfaces, i.e., the contact area between water drop and metal surface is much smaller for the etched surface than for the ground surface (inset in Fig. 6).

Polarization curves of ground $\mathrm{Al}$ and $\mathrm{Al}$ etched in $\mathrm{NaOH}$ for 20 minutes are typical for metals that are poorly corrosion resistant in chloride containing solution (Fig. 6). The cathodic curve is related to reduction of oxygen and the anodic curve to dissolution of $\mathrm{Al}{ }^{14}$ The corrosion potential $\left(E_{\text {corr }}\right)$ of ground and etched $\mathrm{Al}$ was located at $-0.74 \mathrm{~V}$ and $-0.78 \mathrm{~V}$, respectively. Immediately following $E_{\text {corr }}$, the current density increased abruptly indicating anodic dissolution of Al in chloride solution. Etched Al showed larger current densities than ground $\mathrm{Al}\left(3.05 \mu \mathrm{A} \mathrm{cm}^{-2}\right.$ and $0.44 \mu \mathrm{A} \mathrm{cm}^{-2}$, respectively), presumably due to the larger active surface area (electrochemical parameters deduced from polarization curves are presented in Table II). For the ground $\mathrm{Al}$ sample, pre-immersed in CA-18 solution, the current density in $\mathrm{NaCl}$ was reduced and $E_{\text {corr }}$ shifted to a somewhat more positive value, $-0.64 \mathrm{~V}$ (Fig. 6, Table II), presumably due to the presence of the organic layer on the surface. However, the shape of the curve remained quite similar to that of ground Al. In contrast, a significant difference was observed for the CA-18-Al etched sample. The $j_{\text {corr }}$ was smaller by two orders of magnitude and in the anodic range a broad plateau of pseudo-passivity appeared extending up to the breakdown potential $\left(E_{\text {break }}\right)$ of $0.63 \mathrm{~V}$. This plateau reflects the barrier property of the surface layer formed upon immersion of etched Al in CA-18 solution. Such a plateau was not observed for ground $\mathrm{Al}$ immersed in CA-18, which proves that surface preparation is essential for achieving not only superhydrophobicity but also barrier properties of the surface. Note that the ground CA-18-Al sample, though hydrophobic $\left(\theta=138^{\circ} \pm 1^{\circ}\right)$, is not superhydrophobic and does not display barrier properties.

Next, the role of the cooling step following the etching step was considered (Fig. SI-2). Etching in $\mathrm{NaOH}$ produced a hierarchical surface with micrometer-sized cones only when the samples were left to cool down in the $\mathrm{NaOH}$ solution to room temperature (Fig. SI-2a). 
Table II. Electrochemical parameters (corrosion current density $\left(j_{\text {corr }}\right)$, corrosion potential $\left(E_{\text {corr }}\right)$, breakdown potential $\left(E_{\text {break }}\right)$ and passive range $\left.\left(\Delta E=\left|E_{\text {break }}-E_{\text {corr }}\right|\right)\right)$ deduced from potentiodynamic polarization curves (Figs. 6 and 10) recorded for pristine (labelled as Al) or CA covered Al samples $(\mathrm{CA}-x-\mathrm{Al})$ that were either ground or etched for $20 \mathrm{~min}$ in $0.1 \mathrm{M} \mathrm{NaOH}$ at $90^{\circ} \mathrm{C}$. Results are presented as mean \pm standard deviation. Ground Al was immersed in $5 \mathrm{mM}$ ethanol solution of $\mathrm{CA}-18$, whereas etched Al samples were immersed in $5 \mathrm{mM}$ ethanol solution of $\mathrm{CA}$ of different lengths. The wettability of the surface is also denoted.

\begin{tabular}{|c|c|c|c|c|c|}
\hline $\begin{array}{l}\text { Sample / Type of carboxylic } \\
\text { acid }\end{array}$ & $j_{\text {corr }} / \mu \mathrm{A} \mathrm{cm}^{-2}$ & $E_{\text {corr }}$ vs. $\mathrm{Ag} / \mathrm{AgCl} / \mathrm{V}$ & $E_{\text {break }}$ vs. $\mathrm{Ag} / \mathrm{AgCl} / \mathrm{V}$ & $\Delta E / \mathrm{V}$ & Wettability \\
\hline Al ground & $0.44 \pm 0.06$ & $-0.74 \pm 0.01$ & & - & hydrophilic \\
\hline CA-18-Al ground & $0.30 \pm 0.01$ & $-0.64 \pm 0.02$ & & - & hydrophobic \\
\hline CA-6-Al etched & $6.07 \pm 0.03$ & $-0.75 \pm 0.01$ & & - & hydrophilic \\
\hline CA-7-Al etched & $8.35 \pm 0.49$ & $-0.73 \pm 0.01$ & & - & hydrophilic \\
\hline CA-8-Al etched & $2.10 \pm 0.31$ & $-0.73 \pm 0.04$ & & - & hydrophilic \\
\hline CA-14-Al etched & $0.05 \pm 0.01$ & $-0.63 \pm 0.10$ & $0.17 \pm 0.08$ & 0.80 & hydrophobic \\
\hline CA-18-Al etched & $0.07 \pm 0.01$ & $-0.63 \pm 0.05$ & $0.54 \pm 0.13$ & 1.17 & superhydrophobic \\
\hline
\end{tabular}

This may be related to slow kinetics of $\mathrm{Al}$ hydroxide formation and anisotropic growth in the form of cones due to low concentration of $\mathrm{CO}_{2}$ in the solution. ${ }^{53}$ Following immersion in CA-18 solution, both samples were superhydrophobic but only the sample that was etched and cooled down in $\mathrm{NaOH}$ showed a broad plateau of pseudo-passivity (up to $0.63 \mathrm{~V}$ ). For the sample that was not cooled down in $\mathrm{NaOH}$ the extent of this range was significantly narrower (up to $-0.2 \mathrm{~V}$ ). These results confirm that surface morphology and topography are important for adsorption of CA and subsequent barrier protective properties. This observation was elaborated further by studying the effect of etching time on surface roughness and electrochemical behavior. The parameters of immersion in ethanol CA-18 solution were kept constant (concentration $5 \mathrm{mM}$, immersion time $30 \mathrm{~min}$ ) and samples were prepared using different etching times in $\mathrm{NaOH}(5,10$, and 20 minutes). Potentiodynamic polarization curves for $\mathrm{Al}$ samples etched for different etching times in $\mathrm{NaOH}$ and then immersed in CA-18 were recorded in $0.5 \mathrm{M} \mathrm{NaCl}$ (Fig. 7). For reference, the results for ground and etched $\mathrm{Al}$ not immersed in $\mathrm{CA}-18$ are also reported and were already discussed (Fig. 2). The surface roughness increased depending on the etching time, i.e., from $0.29 \pm 0.01 \mu \mathrm{m}$ for ground $\mathrm{Al}$, to $0.76 \pm 0.05 \mu \mathrm{m}, 1.41 \pm 0.05 \mu \mathrm{m}$, and $8.07 \pm 0.65 \mu \mathrm{m}$ after 5,10 , and 20 minutes of etching, respectively (3D profiles for the first and last

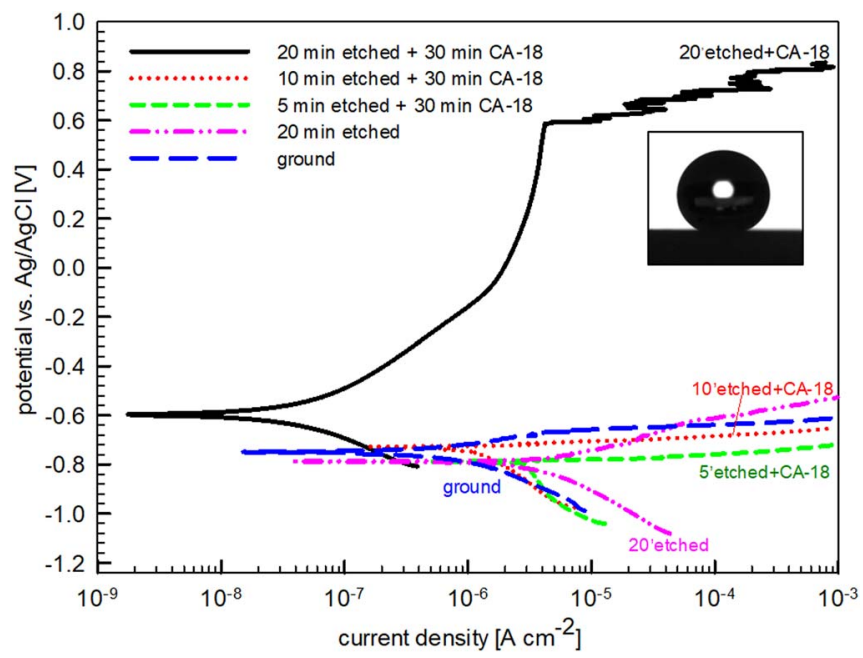

Figure 7. Potentiodynamic polarization curves recorded in $0.5 \mathrm{M} \mathrm{NaCl}$ for ground $\mathrm{Al}, \mathrm{Al}$ etched for 20 minutes in $0.1 \mathrm{M} \mathrm{NaOH}$, and $\mathrm{Al}$ etched for 5, 10 or 20 minutes in $0.1 \mathrm{M} \mathrm{NaOH}$ at $90^{\circ} \mathrm{C}$ and cooled to room temperature, and then immersed in $5 \mathrm{mM}$ ethanol solution of octadecanoic acid (CA-18) for 30 minutes. Scan rate was $1 \mathrm{mV} / \mathrm{s}$. Image of water drop at the surface after 30 minutes immersion in CA-18 is given in the inset. are shown in Fig. 2). When etching in $\mathrm{NaOH}$ for 5 or 10 minutes, and subsequently immersing the sample in CA-18, the shape of the curves did not change significantly compared to the reference sample not exposed to CA-18 (Fig. 7). Only when prior etching was 20 minutes, the subsequent immersion in CA-18 substantially affected the polarization curve and the pseudo-passivity plateau was formed. Etching time in $\mathrm{NaOH}$ affected also the wettability of the surface: superhydrophilic Al samples etched in $\mathrm{NaOH}$ for 5 or 10 minutes became hydrophilic after immersion in CA-18. After being etched in $\mathrm{NaOH}$ for 20 minutes, subsequent immersion in CA-18 resulted in a superhydrophobic surface and exhibited a broad pseudo-passivity region (Fig. 7).

In order to investigate whether the etching time in $\mathrm{NaOH}$ affects only the topography (Fig. 2) or also the chemical composition of the surface layer, we analyzed the samples by XPS analysis. The layer contained $\mathrm{Al}, \mathrm{O}$ and $\mathrm{C}$ as main elements (Fig. 8, Table III). The position of XPS peaks was not significantly affected by the etching time. In the $\mathrm{Al} 2 \mathrm{p}$ spectra the position of peak center confirms the presence of $\mathrm{Al}$ hydroxide regardless the etching time (Fig. 8a). The center of $\mathrm{O} 1 \mathrm{~s}$ peak at $531.4 \mathrm{eV}$ corresponds to the presence of a hydroxylated surface (Fig. 8b). We tried to deconvolute these spectra using component peaks of oxide, hydroxide and adsorbed water (at $c c a .529 .5 \mathrm{eV}, 531 \mathrm{eV}$, and $532.5 \mathrm{eV}$ ) but the results were not sufficiently conclusive to reliably state that etching produced a more hydroxylated surface (i.e., larger hydroxide component peak). The $\mathrm{Al} / \mathrm{O}$ ratio ranges between 0.37 and 0.42 (Table III), depending on the etching time, thus being between the stoichiometric $\mathrm{Al} / \mathrm{O}$ ratio of $\mathrm{Al}(\mathrm{OH})_{3}$ and $\mathrm{AlOOH}$ (Table III). These values are similar to those obtained by EDS analysis (Figs. 3c, 3f and $3 \mathrm{~g}$ ). By increasing the etching time, the fraction of $\mathrm{Al}$ and $\mathrm{O}$ increased and that of carbon decreased (Table III). The latter is due to the decrease in the aliphatic carbon $(\underline{\mathbf{C}}-\mathrm{C}$ and $\underline{\mathbf{C}}-\mathrm{H})$ at $284.8 \mathrm{eV}$, while the peak related to carboxyl groups at $289.3 \mathrm{eV}$ remained similar (Fig. 8c).

Based on the results presented it can be stated that the etching in $\mathrm{NaOH}$ results in the formation of a hydroxylated Al surface; etching time primarily affects the surface topography while the composition (Al/O ratio) remains similar, at least based on the XPS results.

Table III. The composition of surface layers deduced from XPS survey spectra recorded for $\mathrm{Al}$ etched in $0.1 \mathrm{M} \mathrm{NaOH}$ for 5,10 , and 20 minutes (Fig. 8). The $\mathrm{Al} / \mathrm{O}$ ratios, deduced from atomic \%, are also given. For comparison, the stoichiometric $\mathrm{Al} / \mathrm{O}$ ratios are 0.67 in $\mathrm{Al}_{2} \mathrm{O}_{3}, 0.5$ in $\mathrm{AlOOH}$, and 0.33 in $\mathrm{Al}(\mathrm{OH})_{3}$.

Composition / atomic \%

\begin{tabular}{ccccc}
\cline { 2 - 4 } Etching time $/ \min$ & $\mathrm{Al}$ & $\mathrm{O}$ & $\mathrm{C}$ & Ratio Al/O \\
\hline 5 & 21.3 & 57.2 & 21.4 & 0.37 \\
10 & 25.0 & 65.7 & 9.3 & 0.38 \\
20 & 27.7 & 65.5 & 6.8 & 0.42
\end{tabular}




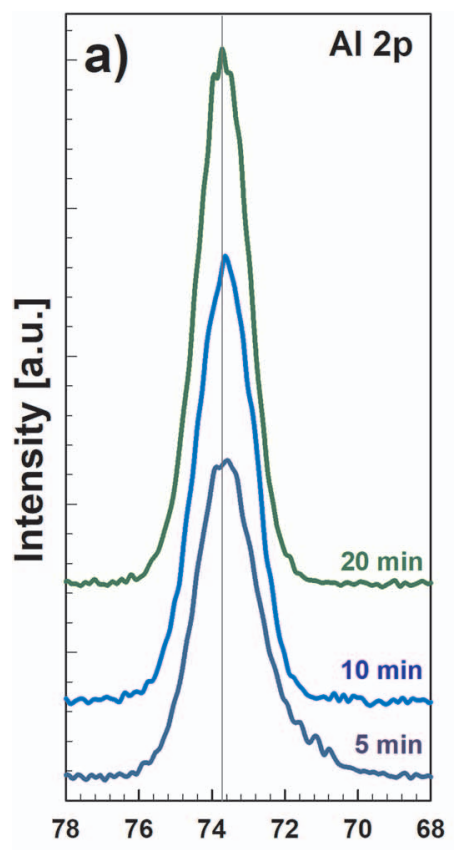

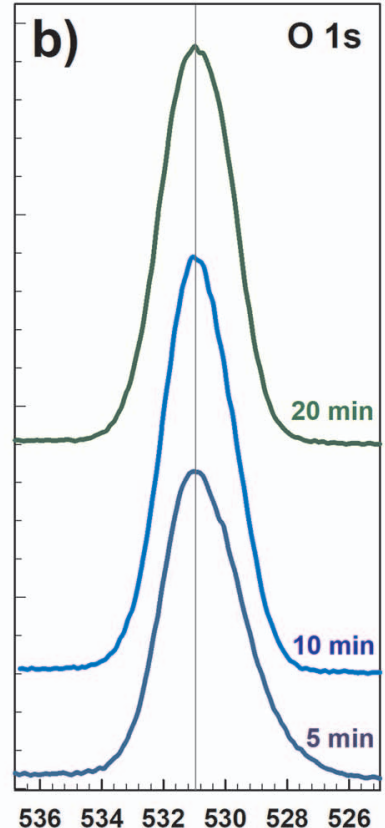

\section{Binding Energy / eV}

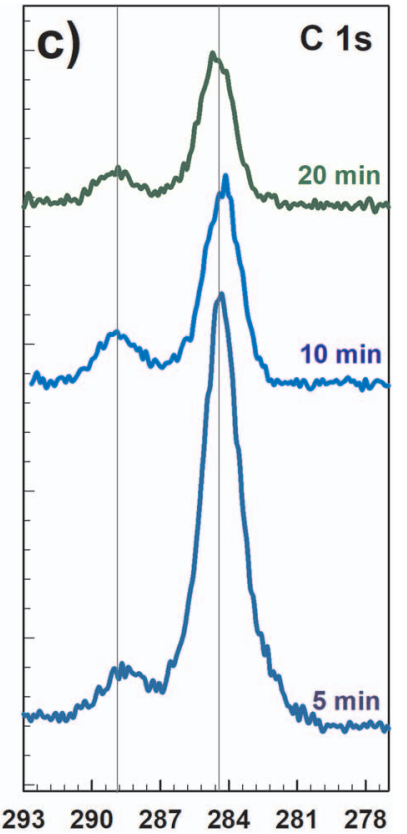

$\begin{array}{llllll}293 & 290 & 287 & 284 & 281 & 278\end{array}$

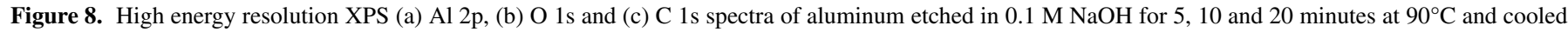

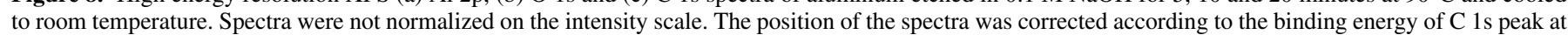
$284.8 \mathrm{eV}$.

Due to large roughness of the surface and a strong charging effect, a dissymmetry of the XPS peaks and a shift of binding energy was observed. Further, sputtering process proceeded non-homogeneously over the surface due to large topographical differences at the surface and, consequently, the measured spectra included contributions from both sputtered and non-sputtered area. At the present point of the investigation, we cannot entirely explain the decrease in carbon content as a function of etching time; it may be related to kinetics of formation of $\mathrm{Al}$ hydroxide during the cooling step, Eq. 2, or, perhaps, the hydroxylated layer formed during etching is less susceptible to carbon contamination.

Electrochemical properties of etched aluminum immersed in ethanol solution of CA: effect of concentration, chain length and time of immersion.-Potentiodynamic polarization curves in $0.5 \mathrm{M}$ $\mathrm{NaCl}$ were recorded for etched $\mathrm{Al}$ immersed in ethanol $\mathrm{CA}$ solution of different concentration, immersion time and length of alkyl chain. First, the effect of concentration was addressed. For the constant etching time in $\mathrm{NaOH}$ of 20 min, the effect of concentration of CA-8 and CA-18 acids was studied for a constant immersion time (30 min). By increasing concentration of CA-8 (from $5 \mathrm{mM}$ to $100 \mathrm{mM}$ ) the current density in cathodic and anodic range decreased, being the smallest for the highest concentration (Fig. 9a). $E_{\text {corr }}$ did not shift considerably indicating that the adsorbed organic layer acts like a barrier layer. However, no pseudo-passivity range was established for CA-8-Al regardless of concentration. In contrast, for all CA-18 concentrations studied, the polarization curves had a similar shape with a broad pseudo-passivity range (Fig. 9b). The breakdown potential was $0.54 \pm 0.13 \mathrm{~V}$ at $5 \mathrm{mM}$ $\mathrm{CA}-18$, and shifted to ca. $0.8 \mathrm{~V}$ at $100 \mathrm{mM}$, possibly indicating better stability of the self-assembled organic layer formed in more concentrated CA solution. However, it seems that in the case of long carboxylic acids, such as CA-18, the concentration has a less significant role on surface properties than the time of etching in $\mathrm{NaOH}$ (Fig. 7). It is noteworthy that the solubility of CA-18 in ethanol is limited at room temperature $\left(62.3 \mathrm{mM}\right.$ at $\left.20^{\circ} \mathrm{C}\right){ }^{76}$ It seems, therefore, that for shorter carboxylic acids such as CA-8, concentration is more important than for longer ones. The effect on the water contact angle also differed.
Whilst for CA-18-Al the surface was for concentrations higher than $5 \mathrm{mM}$ (Fig. 9b), CA-8-Al was hydrophilic at $5 \mathrm{mM}$ and hydrophobic at 50 and $100 \mathrm{mM}$ (Fig. 9a).

Further, the effect of immersion time in ethanol solution of CA18 was studied. The surface became superhydrophobic already after 5 minutes immersion. All polarization curves showed similar shape; at longer immersion time the values of current density were smaller but the breakdown potentials were not significantly different (Fig. SI-3). Given that 30 minutes immersion in CA resulted in good performance, it was chosen for practical reasons for further measurements.

The effect of alkyl chain length of CAs on the polarization curves in $\mathrm{NaCl}$ was studied at an etching time of 20 minutes in $\mathrm{NaOH}, 5 \mathrm{mM}$ concentration, and 30 minutes immersion time in ethanol CA solution (Fig. 10). Carboxylic acids ranging from CA-6 to CA-18 were investigated. Relevant corrosion parameters deduced from polarization curves are presented in Table II together with the type of surface wettability. Shorter CAs, CA-6 and CA-7, acted as corrosion activators as the $j_{\text {corr }}$ values were larger than that of ground and etched Al. $E_{\text {corr }}$ remained similar. For CA-8-Al, CA-9-Al and CA-10-Al, the $j_{\text {corr }}$ values were reduced, especially for the latter. $E_{\text {corr }}$ still remained similar to that of etched Al. The surface wettability changed from superhydrophilic to hydrophilic. For etched CA-14-Al and CA-18$\mathrm{Al}$, however, the shape of polarization curves changed compared to uncoated, ground and etched: the $j_{\text {corr }}$ values were reduced by two orders of magnitude $\mathrm{Al}, E_{\text {corr }}$ shifted to more positive values, and a broad pseudo-passive range was established. This pseudo-passivity range, calculated as $\Delta E=\left|E_{\text {break }}-E_{\text {corr }}\right|$, extended over about $0.80 \mathrm{~V}$ and $1.17 \mathrm{~V}$ for etched CA-14-Al and CA-18-Al, respectively (Table II). The surface wettability changed to hydrophobic for etched CA-14-Al and to superhydrophobic for etched CA-18-Al. Adsorbed organic molecules with longer alkyl chain obviously act as a barrier over the aluminum surface and protect it from corrosion attack in chloride solution. It was reported that the presence of an adsorbed layer

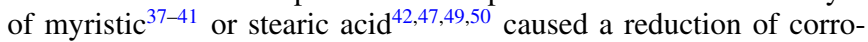
sion current density but, to the best of our knowledge, in none of the published studies such broad extent of the pseudo-passivity region was observed. In general, corrosion resistance of a superhydrophobic 

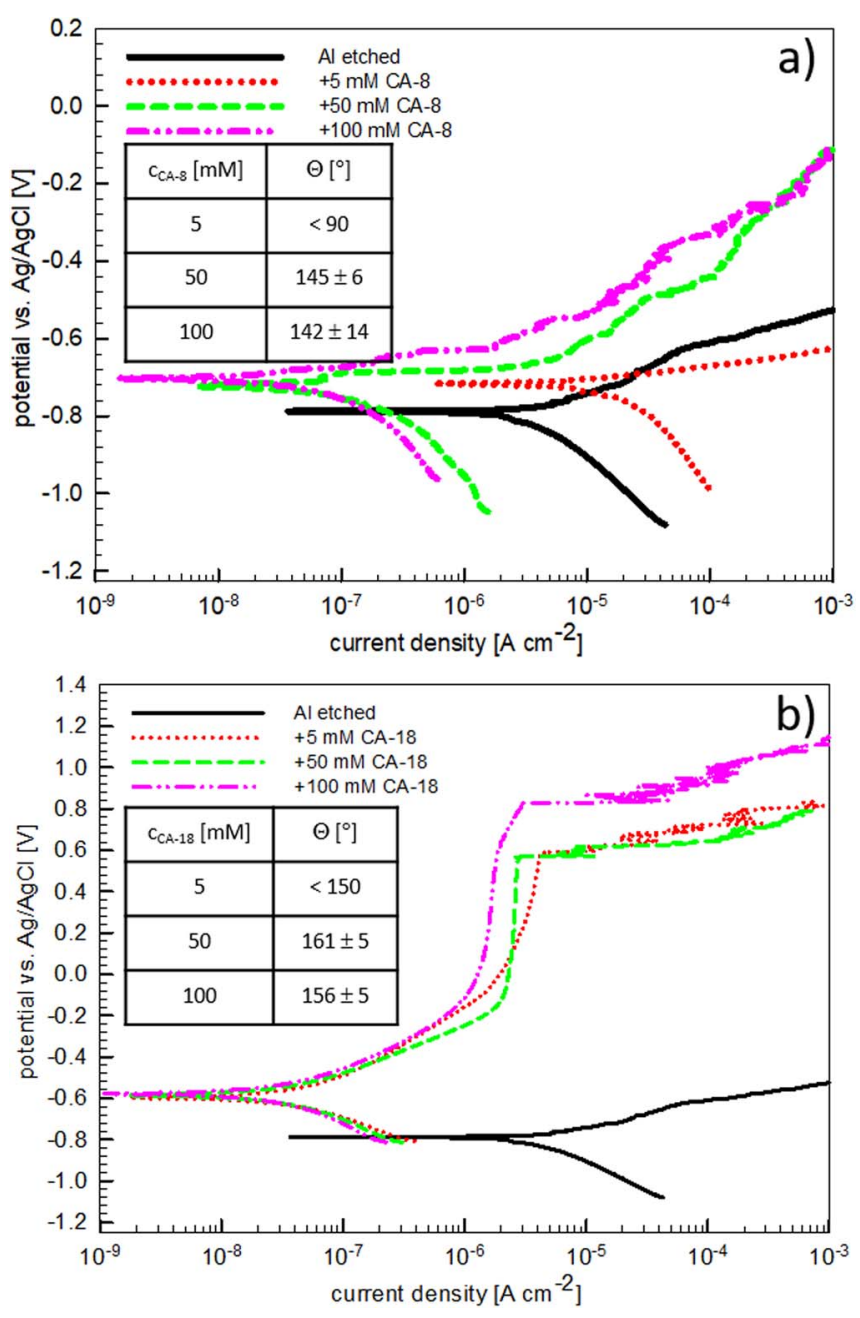

Figure 9. Potentiodynamic polarization curves recorded in $0.5 \mathrm{M} \mathrm{NaCl}$ for $\mathrm{Al}$ etched for 20 minutes in $0.1 \mathrm{M} \mathrm{NaOH}$ at $90^{\circ} \mathrm{C}$, cooled to room temperature, and then immersed in ethanol solution of (a) octanoic acid (CA-8) and (b) octadecanoic acid (CA-18) of different concentrations $(5,50$ and $100 \mathrm{mM})$ for 30 minutes. Scan rate was $1 \mathrm{mV} / \mathrm{s}$. Values of water drop contact angles are given in insets as mean \pm standard deviation.

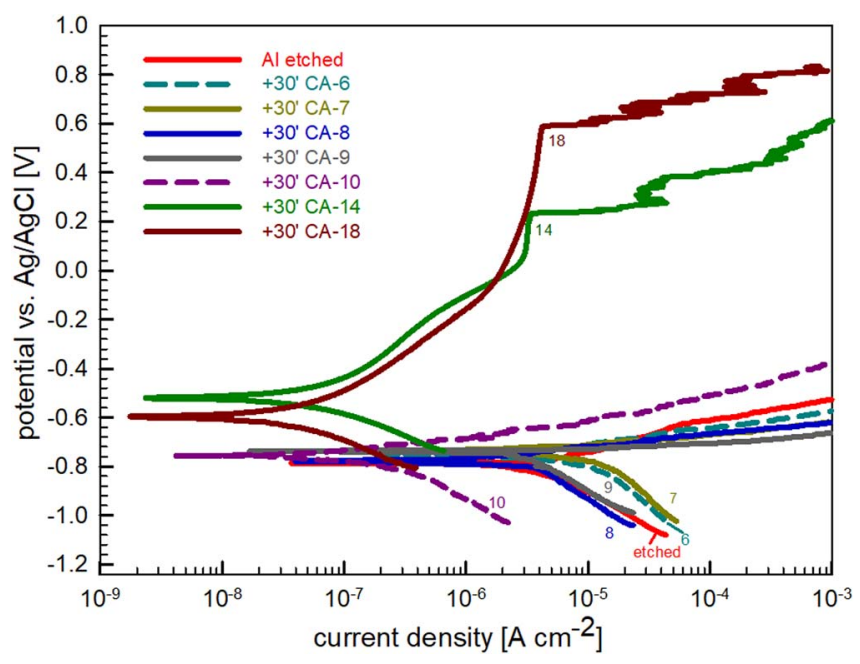

Figure 10. Potentiodynamic polarization curves recorded in $0.5 \mathrm{M} \mathrm{NaCl}$ for $\mathrm{Al}$ etched for 20 minutes in $0.1 \mathrm{M} \mathrm{NaOH}$ at $90^{\circ} \mathrm{C}$ and cooled to room temperature without and with immersion in $5 \mathrm{mM}$ ethanol solution of carboxylic acids of different chain length (CA6 - CA18) for 30 minutes. Scan rate was $1 \mathrm{mV} / \mathrm{s}$.

$$
\begin{gathered}
\text { CA-8@ OH/Al } / \mathrm{O}_{\mathrm{x}} \mathrm{Al}(111) \\
3.54 \mathrm{~nm}^{-2} \\
E_{\mathrm{ads}}=-0.25 \mathrm{~J} / \mathrm{m}^{2}
\end{gathered}
$$

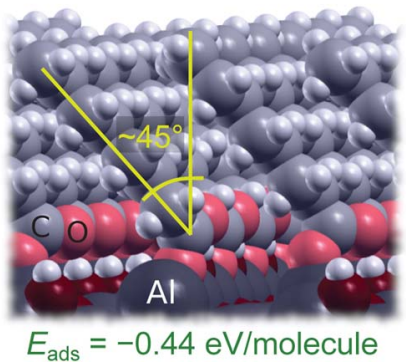

$\mathrm{CA}-8 @ \mathrm{AlOOH} / \mathrm{Al}_{2} \mathrm{O}_{3} / \mathrm{Al}(111)$

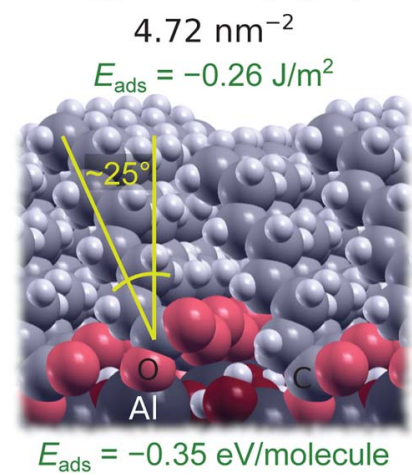

Figure 11. Side-views of SAM of CA-8 on the two surface models for the two investigated coverages $\left(3.54 \mathrm{~nm}^{-2}\right.$ and $\left.4.72 \mathrm{~nm}^{-2}\right)$. Note that the tilting angle is greater for the low coverage $3.54 \mathrm{~nm}^{-2}$ case. The adsorption energy per molecule is also more exothermic for the low coverage case $(-0.44 \mathrm{eV})$ than for the high coverage case $(-0.35 \mathrm{eV})$, however, the total adsorption energies per surface area are almost degenerate, $-0.25 \mathrm{~J} / \mathrm{m}^{2}$ and $-0.26 \mathrm{~J} / \mathrm{m}^{2}$, respectively.

surface is attributed to (i) isolation or significant reduction of contact area between metal substrate and corrosive environment and to (ii) capillarity effect which predicts that the corrosive liquid would be forced out of the pores of the superhydrophobic surface thus protecting it from an aggressive environment. ${ }^{13,77}$

Computational modelling.-To better understand the adsorption of carboxylic acids and their organization within the adsorbed monolayer, PBE- $\mathrm{D}_{0}$ adsorption calculations of CA- 8 and CA-18 molecules were undertaken on two different models of the hydroxylated oxidized $\mathrm{Al}$ surface, as described in the computational details. Two models were used because they have different surface $\mathrm{OH}$ densities, i.e., 7.1 and 14.4 $\mathrm{OH} / \mathrm{nm}^{2}$ for $\mathrm{OH} / \mathrm{Al}_{\mathrm{x}} \mathrm{O} / \mathrm{Al}(111)$ and $\mathrm{AlOOH} / \mathrm{Al}_{2} \mathrm{O}_{3} / \mathrm{Al}(111)$ model, respectively. Note that surface $\mathrm{OH}$ density is thought to be one of the determining factors in the adsorption of organic molecules, including carboxylates, through an acid-base mechanism. ${ }^{78-80}$

Due to different density and site distribution of surface $\mathrm{OH}$ groups on the two surface models, and taking into account the steric footprint of the carboxylic head-group, the maximum reachable CA surface coverage on them is different. In particular, the $\mathrm{CA}$ coverage on $\mathrm{OH} / \mathrm{Al}_{\mathrm{x}} \mathrm{O} / \mathrm{Al}(111)$ can reach $3.54 \mathrm{~nm}^{-2}$ and on $\mathrm{AlOOH} / \mathrm{Al}_{2} \mathrm{O}_{3} / \mathrm{Al}(111)$ it can reach $4.72 \mathrm{~nm}^{-2}$. The latter density is similar to the density of self packed alkane chains $\left(4.8 \mathrm{~nm}^{-2}\right) ;{ }^{81}$ the value obtained from experimental crystal structure of polyethylene ${ }^{82}$ corresponds to $5.8 \mathrm{~nm}^{-2}$. Note that our experimental XPS data are compatible with a full monolayer of carboxylic acids adsorbed (close to) perpendicular to the surface (Fig. 4). However, it is worth mentioning that the uncertainties in the XPS quantification data do not allow precise determination of the tilt angle.

It is well known that the optimization of the lateral interactions between alkyl chains in the self-assembled-monolayer (SAM) induces a tilting of the chains. ${ }^{83-85}$ The tilting of the alkyl chains of $\mathrm{CA}$ is expected to be appreciable at lower coverages as to reduce the inter-chain distances and thus optimize lateral interactions. ${ }^{83}$ In a recent publication ${ }^{86}$ it was suggested that the tilting angle increases as the coverage decreases by a quadratic dependence. The tilting of the molecules is indeed confirmed by current $P B E-\mathrm{D}_{0}$ calculations, as evident from Table IV, which tabulates the CA tilt angles and respective adsorption energies at two different coverages. At lower $3.54 \mathrm{~nm}^{-2}$ coverage the tilting angles, measured with respect to surface normal, range from $45^{\circ}$ to $55^{\circ}$, whereas at high $4.72 \mathrm{~nm}^{-2}$ coverage they range from $25^{\circ}$ to $35^{\circ}$. The two tilting angles are also indicated in Fig. 11, which shows the structure of adsorbed SAM of CA-8 on $\mathrm{OH} / \mathrm{Al}_{\mathrm{x}} \mathrm{O} / \mathrm{Al}(111)$ model at coverage of $3.54 \mathrm{~nm}^{-2}$ and on $\mathrm{AlOOH} / \mathrm{Al}_{2} \mathrm{O}_{3} / \mathrm{Al}(111)$ model at coverage of $4.72 \mathrm{~nm}^{-2}$. We remark that the tilting angles reported in Table IV are likely slightly overes- 
Table IV. PBE- $\mathrm{D}_{0}$ calculated average adsorption energies per molecule (in $\mathrm{eV}$ ) and total adsorption energies per unit surface area (in $\mathrm{J} / \mathrm{m}^{2}$ ) of octanoic (CA-8) and octadecanoic (CA-18) acids at coverages of 3.54 and $4.72 \mathrm{~nm}^{-2}$ on two surface models of the hydroxylated oxidized Al surface. Molecular titling angles, measured against the surface normal, are also reported. The reported adsorption energies of CAs correspond to the condensation reaction, Eq. 5. For comparison also the plain adsorption energy of ethane, Eq. 7, used as a simple model of carbonaceous contamination, is reported at full coverage.

\begin{tabular}{|c|c|c|c|c|c|}
\hline Molecule & Surface model & Coverage $\left(\mathrm{nm}^{-2}\right)$ & Tilt angle $\left(^{\circ}\right)$ & $E_{\text {ads }}(\mathrm{eV})$ & $E_{\mathrm{ads}}\left(\mathrm{J} / \mathrm{m}^{2}\right)$ \\
\hline \multirow[t]{3}{*}{ CA-8 } & $\mathrm{OH} / \mathrm{Al}_{\mathrm{x}} \mathrm{O} / \mathrm{Al}(111)$ & 3.54 & $45^{\mathrm{a}}$ & $-0.44^{\mathrm{a}}$ & $-0.25^{\mathrm{a}}$ \\
\hline & $\mathrm{AlOOH} / \mathrm{Al}_{2} \mathrm{O}_{3} / \mathrm{Al}(111)$ & 3.54 & $50^{\mathrm{b}}$ & $-0.44^{\mathrm{b}}$ & $-0.25^{\mathrm{b}}$ \\
\hline & & 4.72 & $25^{\mathrm{b}}$ & $-0.35^{\mathrm{b}}$ & $-0.26^{\mathrm{b}}$ \\
\hline \multirow[t]{3}{*}{ CA-18 } & $\mathrm{OH} / \mathrm{Al}_{\mathrm{x}} \mathrm{O} / \mathrm{Al}(111)$ & 3.54 & $55^{\mathrm{a}}$ & $-1.45^{\mathrm{a}}$ & $-0.82^{\mathrm{a}}$ \\
\hline & $\mathrm{AlOOH} / \mathrm{Al}_{2} \mathrm{O}_{3} / \mathrm{Al}(111)$ & 3.54 & $50^{\mathrm{b}}$ & $-1.52^{\mathrm{b}}$ & $-0.86^{\mathrm{b}}$ \\
\hline & & 4.72 & $35^{\mathrm{b}}$ & $-1.17^{\mathrm{b}}$ & $-0.88^{\mathrm{b}}$ \\
\hline $\mathrm{C}_{2} \mathrm{H}_{6}$ & $\mathrm{AlOOH} / \mathrm{Al}_{2} \mathrm{O}_{3} / \mathrm{Al}(111)$ & 4.72 & parallel $^{\mathrm{b}}$ & $-0.26^{\mathrm{b}}$ & $-0.20^{\mathrm{b}}$ \\
\hline
\end{tabular}

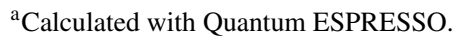

${ }^{\mathrm{b}}$ Calculated with VASP.

timated due to the following two reasons: first, $\mathrm{PBE}-\mathrm{D}_{0}$ slightly overestimate the van der Waals bonding between alkyl chains, because the PBE- $\mathrm{D}_{0}$ predicted nearest-neighbor interchain distance between alkyl chains $(4.0 \AA)$ in the polyethylene crystal is shorter than the experimental value $(4.3 \AA)$; notice that smaller optimal interchain distances result in more tilted molecules and thus larger titling angles. Second, we modelled the SAM as totally ordered structure with rigid alkyl chains (structural relaxation performed at $0 \mathrm{~K}$ ), thus enforcing a rigid picture of the system which obviously includes some degree of freedom.

Table IV also reports adsorption energies. For CAs these correspond to the condensation reaction:

$$
\mathrm{R}-\mathrm{COOH}+\mathrm{OH}^{*} \rightarrow \mathrm{R}-\mathrm{COO}^{*}+\mathrm{H}_{2} \mathrm{O},
$$

where $\mathrm{OH}^{*}$ stands for a surface $\mathrm{OH}$ group and $\mathrm{R}-\mathrm{COO}^{*}$ for adsorbed carboxylate. The corresponding average adsorption energy is calculated as:

$$
E_{\mathrm{ads}}=1 / n\left[E_{n \mathrm{RCOO} / \mathrm{slab}}+n E_{\mathrm{H} 2 \mathrm{O}}-E_{\mathrm{OH} / \mathrm{slab}}-n E_{\mathrm{RCOOH}}\right],
$$

where $n$ is the number of adsorbed carboxylates per supercell, $E_{n \mathrm{RCOO} / \mathrm{slab}}$ is the energy of the carboxylate-slab system and $E_{\mathrm{OH} / \mathrm{slab}}$ is the energy of the pristine hydroxylated slab. $E_{\mathrm{H} 2 \mathrm{O}}$ and $E_{\mathrm{RCOOH}}$ are energies of standalone water and carboxylic acid molecules, respectively. As a simple model of carbonaceous contamination we consider the plain adsorption of ethane $\left(\mathrm{C}_{2} \mathrm{H}_{6}\right)$ and the corresponding adsorption energy is calculated as:

$$
E_{\mathrm{ads}}=1 / n\left[E_{n \mathrm{C} 2 \mathrm{H} 6 / \mathrm{OH} / \mathrm{slab}}-E_{\mathrm{OH} / \mathrm{slab}}-n E_{\mathrm{C} 2 \mathrm{H} 6}\right],
$$

where the energy terms have analogous meaning to the ones described above. No chemical bond is formed between ethane and the surface, hence the molecules are lying on the surface forming a physisorbed layer parallel to the surface.

Table IV reveals that the adsorption of CA via the condensation mechanism is exothermic for all considered cases. The two surface models yield relatively similar adsorption energies at a coverage of $3.54 \mathrm{~nm}^{-2}$, i.e., $-0.44 \mathrm{eV}$ for CA- 8 and about $-1.5 \mathrm{eV}$ for CA18. Several important observations are to be made from the table: (i) the magnitude of adsorption energies increases with increasing chain length, i.e., $\left|E_{\text {ads }}(\mathrm{CA}-18)\right|$ is in general larger than $\left|E_{\text {ads }}(\mathrm{CA}-8)\right|$. Further analysis reveals that the increased stability of larger molecules

Table V. PBE-D 0 calculated values of $E_{\text {ads }}($ at $T=0 \mathrm{~K})$ as well as $T \Delta S_{\text {rot+trans }}$ and $G_{\text {ads }}^{\text {estimated }}$ values (calculated with Eq. 8 at $T=$ $298 \mathrm{~K}$ and $p=1 \mathrm{~atm}$ ) for the condensation adsorption of $\mathrm{CA}-8$ and CA-18. The values of $E_{\text {ads }}$ are taken from Table IV and are here reported as [from, to] range.

\begin{tabular}{lccc} 
Molecule & $E_{\text {ads }}(\mathrm{eV})$ & $T \Delta S_{\text {rot }+ \text { trans }}(\mathrm{eV})$ & $G_{\text {ads }}^{\text {estimated }}(\mathrm{eV})$ \\
\hline CA-8 & {$[-0.35,-0.44]$} & -0.34 & {$[-0.01,-0.10]$} \\
CA-18 & {$[-1.17,-1.52]$} & -0.43 & {$[-0.74,-1.09]$}
\end{tabular}

is due to cohesive lateral interactions within the adsorbed monolayer. In particular, for longer alkyl chains each $\mathrm{CH}_{2}$ group strengthens the cohesion within the adsorbed SAM by about $0.1 \mathrm{eV} /$ molecule due to dispersion London interactions (notice from Fig. 11 the close-packing of alkyl chains in the SAM), whereas the interaction between carboxyl headgroup and surface is not significantly affected by the alkyl chain length. (ii) Although the average adsorption energy per molecule is more exothermic for lower $3.54 \mathrm{~nm}^{-2}$ coverage, the magnitude of total adsorption energy is marginally larger for the full $4.72 \mathrm{~nm}^{-2}$ coverage (the reason is that more molecules are adsorbed per unit area), indicating that the formation of a full monolayer is, in principle, viable. (iii) The total adsorption energy of CA-8 at full coverage is similar to that of ethane, used as a simple model of carbonaceous contamination. This implies that for CA- 8 the thermodynamic driving force for displacing carbonaceous contamination from the surface during adsorption is weak.

It is further worth noting that although the reported $E_{\text {ads }}$ of CAs are only moderately exothermic, the bonding of carboxylates to $\mathrm{Al}$ substrates is nevertheless very strong, above $5 \mathrm{eV}$. The reason is that the values of $E_{\text {ads }}$ correspond to the condensation reaction, Eq. 5, and therefore do not reflect the chemisorption bond strength, because they also contain the cost for breaking the bonds; note that adsorption via the condensation reaction involves both bond-breaking and bond-making.

A drawback of the results presented in Table IV is that they were obtained at $0 \mathrm{~K}$, hence they do not contain thermal corrections to energy and entropy. In this respect, by far the most computationally intensive task is the calculation of the vibrational modes. ${ }^{b}$ However, we noticed in our previous studies of condensation adsorption of silanols on oxidized Al surfaces ${ }^{69,87}$ that vibrational contributions by and large cancel out between reactants and products and as a first approximation they can be neglected. The main thermal contribution to adsorption free energy therefore stems from roto-translational effects, which are relatively straightforward to calculate by using the ideal-gas approximation and the rigid-rotor model. We can thus estimate the adsorption free energy as:

$$
G_{\text {ads }}^{\text {estimated }}(p, T) \approx E_{\text {ads }}(0)-T \Delta S_{\text {rot+trans }}(p, T)
$$

where $E_{\text {ads }}(0)$ is the condensation adsorption energy calculated at $0 \mathrm{~K}$ by Eq. 6 and $\Delta S_{\text {rot-trans }}$ is the roto-translational change in entropy during the reaction. Eq. 8 omits the $p V$ term and roto-translational contributions to thermal energy, because these cancel out for the condensation reaction during which the $\mathrm{CA}$ molecule is immobilized and

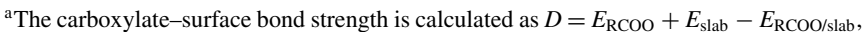
where $E_{\mathrm{RCOO}}$ is the total energy of isolated RCOO radical (i.e., a molecule with the $\mathrm{H}$ atom stripped from the $\mathrm{COOH}$ group) computed with a spin-polarized calculation, $E_{\mathrm{RCOO} / \text { slab }}$ is the total energy of the carboxylate-surface system, and $E_{\text {slab }}$ is the energy of the surface without the carboxylate.

b The current surface models are sufficiently large to make vibrational calculations computationally too demanding for computer resources at our disposal. 

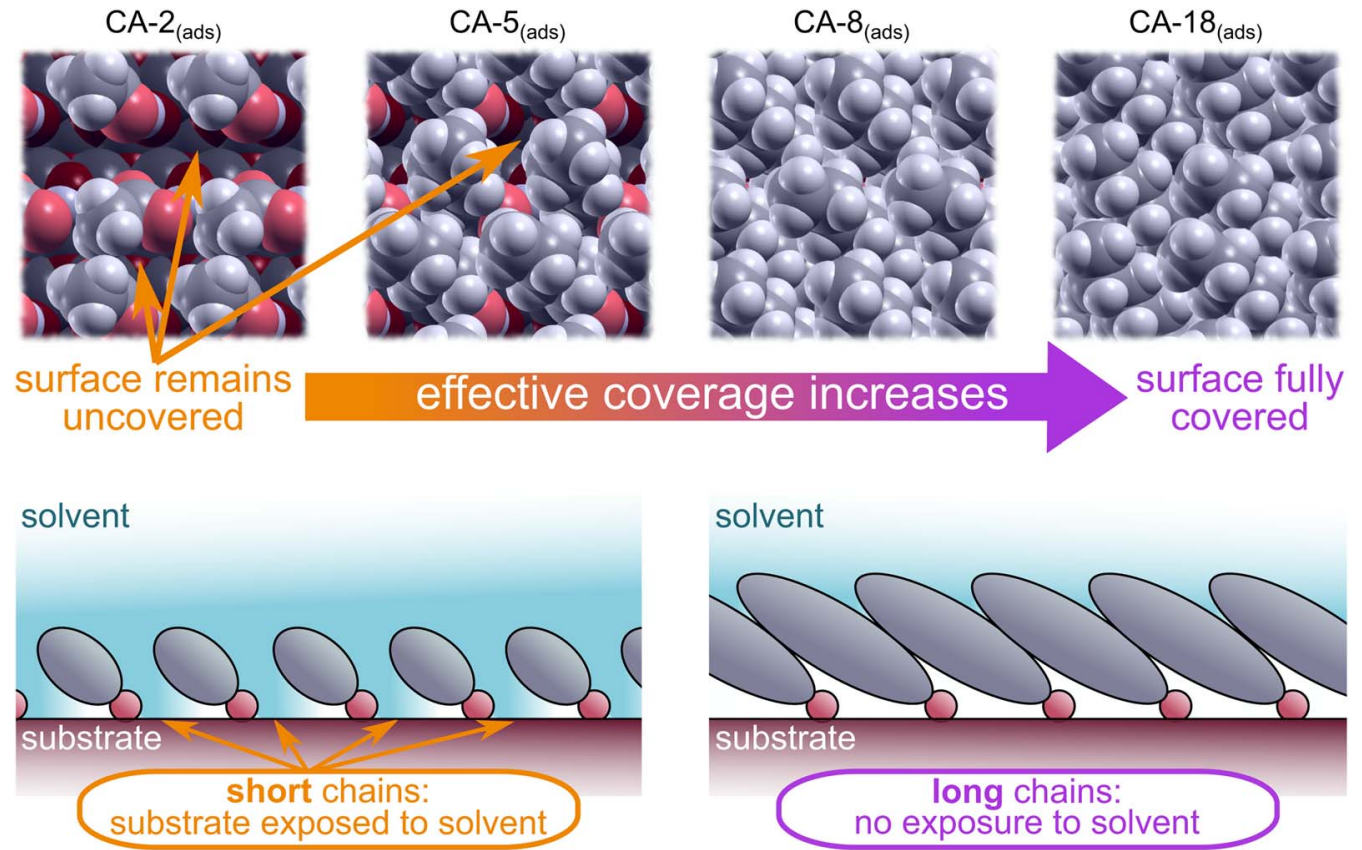

Figure 12. At a given surface density of adsorbed carboxylates, the effective coverage increases with the length of the alkyl chain. Top row shows the top-view of PBE- $\mathrm{D}_{0}$ optimized adsorption configurations of CA-2, CA-5, CA-8, and CA-18 at the surface density of $3.54 \mathrm{~nm}^{-2} \mathrm{on}$ the $\mathrm{OH} / \mathrm{Al} \mathrm{x}_{\mathrm{X}} \mathrm{O} / \mathrm{Al}(111) \mathrm{model}$. At this coverage the molecules with shorter alkyl chains do not completely cover the surface (notice uncovered patches of the surface). However, for molecules with longer alkyl chains (e.g. CA-18) the surface is effectively covered due to molecular tilting. This effect is schematically depicted by side-view sketches in the bottom row.

an $\mathrm{H}_{2} \mathrm{O}$ molecule is liberated. At $T=298 \mathrm{~K}$ and $p=1 \mathrm{~atm}$, the $T S_{\text {rot }+ \text { trans }}$ term for $\mathrm{H}_{2} \mathrm{O}$, CA-8, and CA-18 molecules is $0.58,0.93$, and $1.01 \mathrm{eV}$, respectively. The resulting $T \Delta S_{\text {rot trans }}$ and $G_{\text {ads }}^{\text {estimated }}$ values for the condensation adsorption of CA-8 and CA-18 are tabulated in Table V. It can be seen that thermal effects favor the adsorption of CA-18 relative to CA-8, because for the latter the adsorption free energies, estimated with Eq. 8, are close to zero, whereas for CA-18 they are significantly exergonic, being on the order of $-1 \mathrm{eV}$.

On the basis of results presented above, we can build a sound picture of why CA-18 is a better corrosion inhibitor than CA-8. First, the longer alkyl chains result in a more stable molecular film on the surface, due to increased lateral cohesive forces. Secondly, the greater stability of the adsorbed molecular film provides a larger thermodynamic force for displacing carbonaceous contamination from the surface. Thirdly, longer alkyl chains enable greater effective coverage, even for coverages that are nominally too small for the carboxylic head-groups to fully cover the surfaces. Namely, due to molecular tilting the longer alkyl chains can cover the exposed patches of the surface and thus close the open "gaps" as shown schematically in Fig. 12. Finally, let us remark that an ongoing DFT work on related CA-6 and CA-12 films on $\mathrm{AlOOH} / \mathrm{Al}_{2} \mathrm{O}_{3} / \mathrm{Al}(111)$ model is being performed to characterize the protective effect of organic layers against penetration of $\mathrm{Cl}^{-}$ions into the surface. ${ }^{88}$ Preliminary results indicate that the $\mathrm{Cl}^{-}$ ion diffuses through the CA-6 layer without a barrier, whereas a barrier is found for the diffusion of the same anion through the CA-12 film, which additionally attests to the protective nature of CA inhibitors with longer alkyl chains.

Durability and self-cleaning testing of etched aluminum immersed in ethanol solution of CA.-A superhydrophobic surface is also expected to be durable in harsh environments. ${ }^{89}$ Durability of superhydrophobic properties of self-assembled layers formed during immersion of etched Al samples in ethanol solutions of $5 \mathrm{mM} \mathrm{CA}-18$ was tested by measuring the water contact angle during the course of $48 \mathrm{~h}$ immersion in different solutions: $3.5 \mathrm{wt} \% \mathrm{NaCl}, \mathrm{NaOH}$ at $\mathrm{pH} 11$, and $\mathrm{HCl}$ at $\mathrm{pH}$ 4. These conditions are even harsher than those proposed in protocols for durability testing in alkaline and acidic conditions. ${ }^{89}$ In particular, we increased the time of the duration test $(48 \mathrm{~h}$ instead of $10 \mathrm{~h}$ ) and used more extreme $\mathrm{pH}$ conditions $(\mathrm{pH}=11$ and $\mathrm{pH}=4$ instead of $\mathrm{pH}=8.5$ and $\mathrm{pH}=6$ ). A graph showing the dependence of the contact angle vs. immersion time is depicted in Fig. 13. The best durability was achieved in $3.5 \mathrm{wt} \% \mathrm{NaCl}$ solution where $\theta$ remained above $140^{\circ}$. Somewhat smaller, but still excellent durability, with $\theta>$ $130^{\circ}$ was obtained in $\mathrm{HCl}$ solution at $\mathrm{pH} 4$. In contrast, in $\mathrm{NaOH}$ solution superhydrophobic properties of the surface were lost somewhere

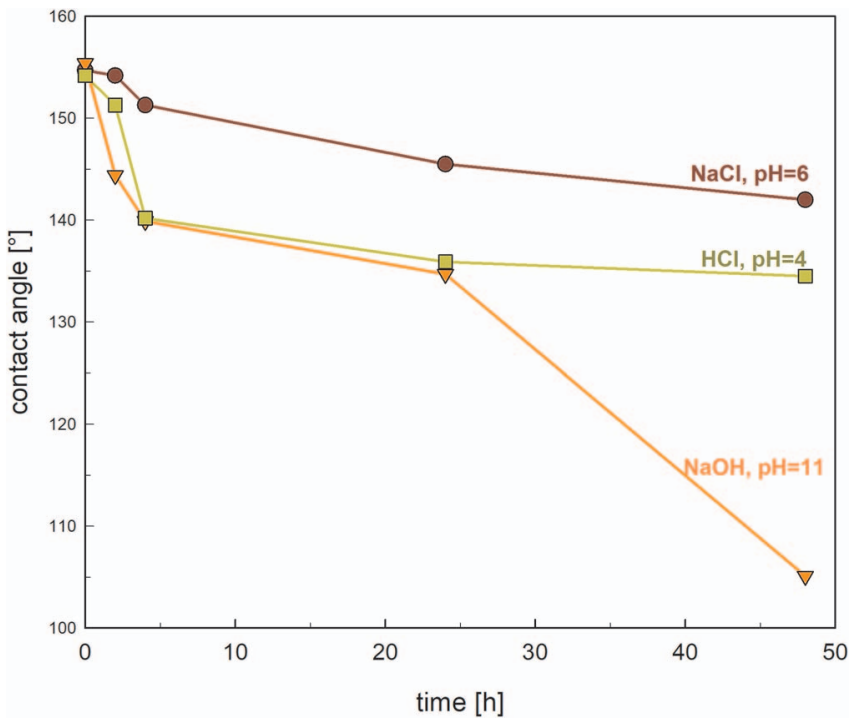

Figure 13. Durability test for $\mathrm{Al}$ etched for 20 minutes in $0.1 \mathrm{M} \mathrm{NaOH}$ at $90^{\circ} \mathrm{C}$, cooled to room temperature and then immersed in ethanol solution of $5 \mathrm{mM}$ octadecanoic acid (CA-18) for 30 minutes. Durability was tested by measuring the contact angle of the water drop at 1, 5, 24 and 48 hours during the course of immersion in $\mathrm{NaCl}(\mathrm{pH}=6,3.5 \mathrm{wt} \%), \mathrm{NaOH}(\mathrm{pH}=11)$, and $\mathrm{HCl}(\mathrm{pH}=4)$. Mean values of water drop contact angles are shown and lines are drawn to guide the eye. 


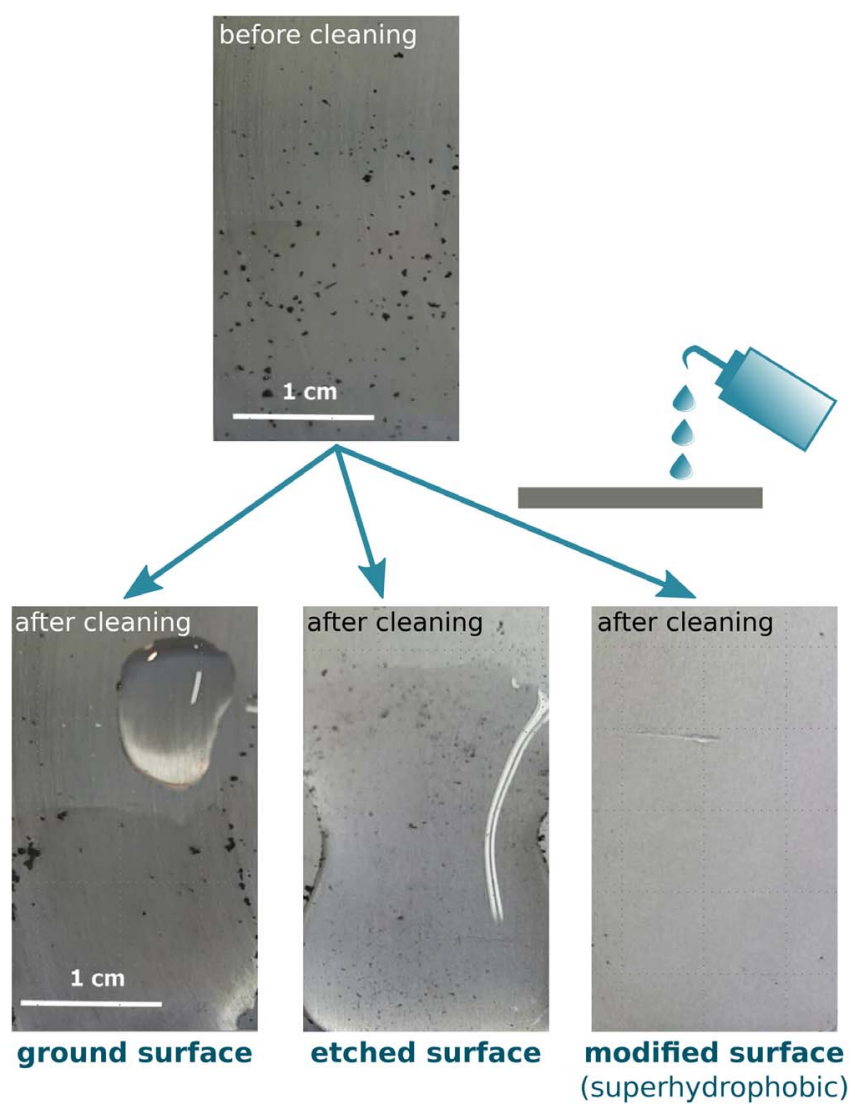

Figure 14. Snapshots recorded before (upper panel) and after (lower panel) cleaning of different surfaces: ground $\mathrm{Al}, \mathrm{Al}$ etched in $0.1 \mathrm{M} \mathrm{NaOH}$ at $90^{\circ} \mathrm{C}$, cooled to room temperature and $\mathrm{Al}$ etched in $0.1 \mathrm{M} \mathrm{NaOH}$ and then immersed in ethanol solution of $5 \mathrm{mM}$ octadecanoic acid (CA-18) for 30 minutes. Carbon particles were used for the self-cleaning test. Video film is presented in Supplementary material (Video information VI-1).

between $24 \mathrm{~h}$ and $48 \mathrm{~h}$ of continuous immersion. In particular, at $48 \mathrm{~h}$ the value of $\theta$ was $105^{\circ} \pm 2^{\circ}$.

An important property of superhydrophobic surfaces is the ability of self-cleaning. To test whether CA-modified Al surface exhibits the self-cleaning ability, the surfaces of ground $\mathrm{Al}, \mathrm{NaOH}$-etched $\mathrm{Al}$, and etched CA-18-Al samples were covered by carbon particles (Fig. 14). Due to different wettability of these surfaces, water drops remained on the surface for ground and etched Al. In contrast, for CA-18-Al, water drops bounced away from the surface taking the carbon particles with them. After the test, the superhydrophobic surface was clean, whereas ground and etched surfaces were still covered by particles (Fig. 14 and Video information VI-1).

The ability of a superhydrophobic surface to resist ice formation is important in numerous applications, such as airplanes, electric power lines, and wind-turbines.7,12 The freezing time of water droplets on superhydrophobic surfaces is significantly retarded because the heat transfer between the droplet and the solid surface is weakened by the trapped air in the cavities under the liquid-solid interface. ${ }^{7}$ Further, the ice adhesion strength to a superhydrophobic surface is less than that to a surface of higher wettability. ${ }^{7}$ We have recently demonstrated the ice freezing and ice melting delay on a superhydrophobic aluminum surface fabricated in a mixture of $\mathrm{NaOH}$ and fluorosilanes. ${ }^{90}$ Superhydrophobic layers based on myristic acid ${ }^{38}$ and ceria-stearic coating ${ }^{46}$ on $\mathrm{Al}$ were demonstrated to exhibit anti-icing ability. In the present work we used the ice melting delay test to demonstrate the ability of the surface to reduce the adhesion of ice which would in practical applications imply easier ice removal. Due to hierarchically rough surface and coverage by long chain octadecanoic acid of low surface energy the superhydrophobic surface exhibited longer melting time of over $350 \mathrm{~s}$ compared to $240 \mathrm{~s}$ on ground aluminum (Video information VI-2).

\section{Conclusions}

1. The possibility to prepare superhydrophobic and corrosion resistant coatings on aluminum using simple and non-toxic carboxylic acids (CAs) was explored in the present study. It was tackled on three levels: (i) fabrication of adsorbed organic layers, which was successful on $\mathrm{Al}$ etched in alkaline $\mathrm{NaOH}$ solution; (ii) their experimental characterization using electrochemical and surfaceanalytical (SEM/EDS, XPS, and ToF-SIMS) techniques, roughness, and wettability measurements; and (iii) DFT modelling of adhesion and self-assembly of CAs on oxidized Al substrates.

2. Kinetics of etching and cooling were found essential for the formation of a superhydrophylic and hierarchical micro- and nanostructured aluminum hydroxide. Once such a surface is immersed in ethanol solution of carboxylic acid, the CA molecules can efficiently adsorb on it and make the surface superhydrophobic and corrosion resistant. The change in wettability and degree of corrosion protection are dependent on a number of factors. Rough surface topography and presence of a hydroxylated surface layer are crucial for subsequent adsorption of carboxylic acids. The length of alkyl chain of carboxylic acid, acid concentration and immersion time determine the final surface properties.

3. Seven carboxylic acids ranging from hexanoic to octadecanoic were investigated. At constant immersion time (30 minutes) and acid concentration $(5 \mathrm{mM})$, short CAs (CA-6 and CA-7) act as corrosion activators, longer CAs (CA-8, CA-9 and CA-10) act as weak corrosion inhibitors, but only long chain acids (CA-14 and, especially, CA-18) are efficient corrosion inhibitors that also provide barrier protection of Al. Upon immersion in CAs, wettability of etched $\mathrm{Al}$ changes from superhydrophilic to hydrophilic for CAs $\leq$ CA-10, to hydrophobic for CA-14, and to superhydrophobic for CA-18. XPS and ToF-SIMS analyses corroborated that short and long carboxylic acid (CA-8 and CA-18) form an adsorbed organic layer. Therefore, an increase in hydrophobicity does not necessarily imply significant improvement in barrier corrosion properties.

4. The formation of a carboxylate layer on Al surface upon immersion in CA solution was the basis for DFT modelling. It is proposed that the adsorption proceeds via the condensation mechanism. The magnitude of adsorption energy increases with length of alkyl chains and additionally leads to increased cohesive lateral forces resulting in a more stable molecular film on the surface. Furthermore, molecules with shorter alkyl chain do not completely cover the surface, while those with long alkyl chains, like octadecanoic acid, effectively cover the surface due to molecular tilting.

5. When prepared under suitable conditions, an adsorbed (carboxylate) layer is formed on $\mathrm{Al}$ which is superhydrophobic and acts as a corrosion barrier in $\mathrm{NaCl}$. This layer is demonstrated to be durable and chemically stable in neutral and acidic chloride solution with contact angles remaining above $140^{\circ}$ for $48 \mathrm{~h}$. In alkaline solution of $\mathrm{pH}=11$ the layer is less durable. Self-cleaning and icemelting delay properties of superhydrophobic Al surfaces were demonstrated and can be exploited for practical applications.

\section{Acknowledgments}

This work is a part of M-ERA.NET project entitled "Design of corrosion resistant coating targeted for versatile applications" (acronym COR_ID). The financial support of the project by MESS (Ministry of Education, Science and Sport of Republic of Slovenia) and ANR (The French National Research Agency) is acknowledged. Région Ile-de-France is acknowledged for partial support of the ToF-SIMS equipment. The GENCI French National Agency is acknowledged for attribution of computational time under the program A0040802217. Slovenian Research Agency is acknowledged for financial support 
(core funding No. P2-0393). The authors thank Dolores Zimerl, MSc, for her valuable technical help in sample preparation and characterization. SEM/EDS analysis was performed by Gregor Kapun, MSc (on Ultra+ instrument) and Barbara Kapun, BSc (JEOL JSM instrument). XPS analysis at the Jožef Stefan Institute was performed by Prof. Janez Kovač and Tatjana Filipič, BSc. Their contributions are acknowledged.

\section{ORCID}

I. Milošev (i) https://orcid.org/0000-0002-7633-9954

M. Poberžnik (10 https://orcid.org/0000-0002-4866-4346

A. Kokalj (D) https://orcid.org/0000-0001-7237-0041

\section{References}

1. J. Genzer and K. Efimenko, "Recent developments in superhydrophobic surfaces and their relevance to marine fouling; a review," Biofouling, 22, 339 (2006).

2. N. J. Shirtcliffe, G. McHale, S. Atherton, and M. I. Newton, "An introduction to superhydrophobicity," Adv. Colloid Interface Sci., 161, 124 (2010).

3. I. Sas, R. E. Gorga, J. A. Joines, and K. A. Thoney, "Literature review on superhydrophobic self-cleaning surfaces produced by electroplating", J. Poly. Sci. Part B Polym Phys., 50, 824 (2012)

4. S. S. Latthe, A. B. Gurav, C. S. Maruti, and R. S. Vhatkar, "Recent progress in preparation of superhydrophobic surfaces: A review," J. Surf. Eng. Mater. Adv. Technol., 2, 76 (2012).

5. A. M. A. Mohamed, A. M. Abdullah, and N. A. Younan, "Corrosion behavior of superhydrophobic surfaces: A review," Arab. J. Chem., 8, 749 (2015).

6. J. T. Simpson, S. R. Hunter, and T. Aytug, "Superhydrophobic materials and coatings: a review," Rep. Prog. Phys., 78, 086501 (2015).

7. P. Zhang and F. Y. Lv, "A review of the recent advances in superhydrophobic surfaces and the emerging energy-related applications," Energy, 82, 1068 (2015).

8. Y. Si and Z. Guo, "Superhydrophobic nanocoatings: from materials to fabrication and to applications," Nanoscale, 7, 5922 (2015).

9. C. Zhan-Fang, Q. Pei, C. Pei, W. Xin, L. Guang-Yi, W. Shuai, and Z. Hong, "Superhydrophobic coatings used in corrosion protection of metal material: review, discussion and prospects," Metall. Res. Technol., 114, 203 (2017).

10. A. Fihri, E. Bovero, A. Al-Shahrani, A. Al-Ghamdi, and G. Alabedi, "Recent progress in superhydrophobic coatings used for steel protection: A review," Colloids Surf. A Physichem. Eng. Aspects, 520, 378 (2017).

11. S. Das, S. Kumar, S. K. Samal, S. Mohanty, and S. K. Nayak, "A review on superhydrophobic polymer coatings: Recent development and applications," Ind. Eng. Chem. Res., 57, 2727 (2018).

12. J. Jeevahan, M. Chandrasekaran, G. Britto Joseph, R. B. Durairaj, and G. Mageshwaran, "Superhydrophobic surfaces: a review on fundamentals, applications, and challenges," J. Coat. Res. Technol., 15, 231 (2018).

13. Gh. Barati Darband, M. Aliofkhazraei, S. Khorsand, S. Sokhanvar, and A. Kaboli, "Science and Engineering of superhydrophobic surfaces: Review of corrosion resistance, chemical and mechanical stability", Arab. J. Chem., in press.

14. Ch. Vargel, Corrosion of Aluminum, 1st edition, Elsevier Ltd., Oxford, UK, 2004.

15. https://echa.europa.eu/substances-restricted-under-reach/-/dislist/details/ $0 \mathrm{~b} 0236 \mathrm{e} 1807 \mathrm{e} 2 \mathrm{bc} 1$.

16. R. Grover Wankhede, S. Morey, A. S. Khanna, and N. Birbilis, "Development of water-repellent organic-inorganic hybrid sol-gel coatings on aluminum using short chain perfluoro polymer emulsion," Appl. Surf. Sci., 283, 1051 (2013).

17. J. Liang, Y. Hu, Y. Wu, and H. Chen, "Facile formation of superhydrophobic silicabased surface on aluminum substrate with tetraethylorthosilicate and vinyltritriethoxysilane as co-precursor and its corrosion resistant performance in corrosive $\mathrm{NaCl}$ aqueous solution," Surf. Coat. Techol., 240, 145 (2014).

18. H. Wang, Z. Liu, E. Wang, R. Yuan, D. Gao, X. Zhang, and Y. Zhu, "A robust superhydrophobic PVDF composite coating with wear/corrosion-resistance properties," Appl. Surf. Sci., 332, 518 (2015).

19. P. E. Hintze and L. Marina Calle, "Electrochemical properties and corrosion protection of organosilane self-assembled monolayers on aluminum 2024-T3," Electrochim. Acta, 51, 1761 (2006).

20. P. M. Barkhudarov, P. B. Shah, E. B. Watkins, D. A. Doshi, C. J. Brinker, and J. Majewski, "Corrosion inhibition using superhydrophobic films," Corros. Sci., 50, 897 (2008).

21. B. Yin, L. Fang, J. Hu, A. Q. Tang, J. He, and Mao J.H, "A facile method for fabrication of superhydrophobic coating on aluminum alloy," Surf. Interface Anal., 44, 439 (2012)

22. T. Maitra, C. Antonini, M. Auf der Mauer, C. Stamatopoulos, M. K. Tiwari, and D. Poulikakos, "Hierarchically nanotextured surface maintaining superhydrophobicity under severely adverse conditions," Nanoscale, 6, 8710 (2014).

23. Y. Cheng, S. Lu, and W. Xu, "Controllable wettability of micro- and nano-dendritic structures formed on aluminum substrates," New J. Chem., 39, 6602 (2015).

24. Y. Cheng, S. Lu, W. Xu, and H. Wen, "Fabrication of $\mathrm{Au}-\mathrm{AlAu}_{4}-\mathrm{Al}_{2} \mathrm{O}_{3}$ superhydrophobic surface and its corrosion resistance," RSC Adv., 5, 15387 (2015).

25. H. Zhang, L. Yin, S. Shi, X. Liu, Y. Wang, and F. Wang, "Facile and fast fabrication method for mechanically robust superhydrophobic surface on aluminum foil," Microelectron. Eng., 141, 238 (2015).
26. J. Sun, C. Wang, J. Song, L. Huang, Y. Sun, Z. Liu, C. Zhao, and Y. Li, "Multifunctional application of oil-infused slippery Al surface: from anti-icing to corrosion resistance," J. Mater. Sci., 53, 16099 (2018).

27. G. Žerjav and I. Milošev, "Carboxylic acids as corrosion inhibitors for $\mathrm{Cu}, \mathrm{Zn}$ and brasses in simulated urban rain," Int. J. Electrochem. Sci., 9, 2696 (2014).

28. G. Žerjav and I. Milošev, "Protection of copper against corrosion in simulated urban rain by the combined action of benzotriazole, 2-mercaptobenzimidazole and stearic acid," Corros. Sci., 98, 180 (2015).

29. G. Žerjav and I. Milošev, "Corrosion protection of brasses and zinc in simulated urban rain. Part I: Individual inhibitors benzotriazole, 2-mercaptobenzimidazole and stearic acid," Mater. Corr., 66, 1402 (2015).

30. G. Žerjav and I. Milošev, "Corrosion protection of brasses and zinc in simulated urban rain. Part II: The combination of inhibitors benzotriazole and 2mercaptobenzimidazole with stearic acid," Mater. Corr., 67, 92 (2016).

31. G. Žerjav, A. Lanzutti, F. Andreatta, L. Fedrizzi, and I. Milošev, "Characterization of self-assembled layers made with stearic acid, benzotriazole and 2mercaptobenzimidazole on surface of copper for corrosion protection in simulated urban rain," Mater. Corr., 68, 30 (2017).

32. I. Milošev, T. Kosec, and M. Bele, "The formation of hydrophobic and corrosion resistant surfaces on copper and bronze by treatment in myristic acid," J. Appl. Electrochem., 40, 1317 (2010).

33. T. Kosec, A. Legat, and I. Milošev, "The comparison of organic protective layers on bronze and copper," Prog. Org. Coat., 69, 199 (2010).

34. S. Wang, L. Feng, and L. Jiang, "One-step solution-immersion process for the fabrication of stable bionic superhydrophobic surfaces," Adv. Mater, 18, 767 (2016).

35. Y. Li, C. Tan, G. Qi, J. Guo, X. Wang, and S. Zhang, "Decanoate conversion layer with improved corrosion protection for magnesium alloy," Corros. Sci., 70, 229 (2013).

36. E. Richard, C. Anandan, and S. T. Aruna, "Fabrication of superhydrophobic zinc stearate hierarchical surfaces from different precursors," J. Mater. Manuf. Proc., 32, 1171 (2016).

37. S. Zheng, C. Li, Q. Fu, M. Li, W. Hu, Q. Wang, M. Du, X. Liu, and Z. Chen, "Fabrication of self-cleaning superhydrophobic surface on aluminum alloys with excellent corrosion resistance," Surf. Coat.Technol., 276, 341 (2015).

38. S. Zheng, C. Li, Q. Fu, W. Hu, T. Xiang, Q. Wang, M. Du, X. Liu, and Z. Chen, ”Development of stable superhydrophobic coatings on aluminum surface for corrosionresistant, self-cleaning, and anti-icing applications", Mater. Design, 93, 261 (2016).

39. Y. Yin, Tao Liu, S. Chen, Tong Liu, and S. Cheng, "Structure stability and corrosion inhibition of super-hydrophobic film on aluminum in sea water," Appl. Surf. Sci., 255, 2978 (2018)

40. Tao Liu, L. Dong, Tong Liu, and Y. Yin, "Investigations on reducing microbiologically-influenced corrosion on aluminum by using super-hydrophobic surfaces," Electrochim. Acta, 55, 5281 (2010).

41. Y. Liu, J. Liu, S. Li, Y. Wang, Z. Han, and L. Ren, "One-step method for fabrication of biomimetic superhydrophobic surface on aluminum alloy," Colloids Surf. A Physichem. Eng. Aspects, 466, 125 (2015).

42. Y. Huang, D. K. Sarkar, and X.-Grant Chen, "Fabrication of corrosion resistance micro-nanostructured superhydrophobic anodized aluminum in a one-step electrodeposition process," Metals, 6, 47 (2016).

43. B. Zhang, X. Zhao, Y. Li, and B. Hou, "Fabrication of durable anticorrosion superhydrophobic surfaces on aluminum substrates via a facile one-step electrodeposition approach," RSC Adv., 6, 35455 (2016).

44. D. Xie and W. Li, "A novel simple approach to preparation of superhydrophobic surfaces of aluminum alloys," Appl. Surf. Sci., 258, 1004 (2011).

45. R. Wu, G. Chao, H. Jiang, Y. Hu, and A. Pan, "The superhydrophobic aluminum surface prepared by different methods," Mater. Letters, 142, 176 (2015)

46. F. J. M. Ruiz-Cabello, P. Ibañez-Ibañez, G. Paz-Gomez, M. Cabrerizo-Vilchez, and M. A. Rodriguez-Valverde, "Fabrication of superhydrophobic metal surfaces for antiicing applications," J. Vis. Exp., 138, e57635 (2018).

47. D. Zang, R. Zu, W. Zhang, J. Wu, X. Yu, and Y. Zhang, "Stearic acid modified aluminum surfaces with controlled wetting properties and corrosion resistance," Corros. Sci., 83, 86 (2014)

48. L. Feng, Y. Che, Y. Liu, X. Qiang, and Y. Wang, "Fabrication of superhydrophobic aluminum alloy surface with excellent corrosion resistance by a facile and environmentfriendly method," Appl. Surf. Sci., 283, 367 (2013).

49. L. Feng, Z. Yan, X. Qiang, Y. Liu, and Y. Wang, "Facile formation of superhydrophobic aluminum alloy surface and corrosion-resistant behavior," Appl. Phys. A, 12, 165 (2016).

50. L. Feng, H. Zhang, Z. Wang, and Y. Liu, "Superhydrophobic aluminum alloy surface: Fabrication, structure, and corrosion resistance," Colloids Surf. A Physichem. Eng. Aspects, 441, 319 (2014).

51. J. Wysocka, M. Cieslik, S. Krakowiak, and J. Ryl, "Carboxylic acis as efficient corrosion inhibitors of aluminum alloys in alkaline media," Electrochim. Acta, 289, 175 (2018).

52. A. R. Madram, F. Shokri, M. R. Sovizi, and H. Kalhor, "Aromatic carboxylic acids as corrosion inhibitors for aluminum in alkaline solution," Portug. Electrochim. Acta, 34, 395 (2016).

53. L. Liu, X. Feng, and M. Guo, "Eco-friendly fabrication of superhydrophobic bayerite array on Al foil via an etching and growth process," J. Phys. Chem. C, 117, 25519 (2013).

54. R. Viroulaud, J. Swiatowska, A. Seyeux, S. Zanna, J. Tardelli, and P. Marcus, "Influence of surface pretreatments on the quality of trivalent chromium process coatings on aluminum alloy," App. Surf. Sci., 423, 927 (2017).

55. M. Ely, J. Swiatowska, A. Seyeux, S. Zanna, and P. Marcus, "Role of Post-Treatment in Improved Corrosion Behavior of Trivalent Chromium Protection (TCP) Coating Deposited on Aluminum Alloy 2024-T3," J. Electrochem. Soc., 164, C276 (2017). 
56. D. Costa, T. Ribeiro, P. Cornette, and P. Marcus, "DFT modeling of corrosion inhibition by organic molecules: carboxylates as inhibitors of aluminum corrosion," $J$. Phys. Chem. C, 120, 28607 (2016).

57. J. H. Scofield, "Hartree-Slater subshell photoionization cross-sections at 1254 and 1487 eV," J. Electron Spectrsc. Relat. Phenom., 8, 129 (1976).

58. S. Tanuma, C. J. Powell, and D. R. Penn, "Calculations of electron inelastic mean free paths. II. Data for 27 elements over the 50-2000 eV range," Surf. Interface Anal., 17, 911 (1991)

59. J. P. Perdew, K. Burke, and M. Ernzerhof, "Generalized Gradient Approximation Made Simple," Phys. Rev. Lett., 77, 3865 (1996).

60. P. Giannozzi, O. Andreussi, T. Brumme, O. Bunau, M. B. Nardelli, M. Calandra, R. Car, C. Cavazzoni, D Ceresoli, M. Cococcioni, N. Colonna, I. Carnimeo, A. D. Corso, S. de Gironcoli, P. Delugas, R. A. di Stasio Jr, A Ferretti, A. Floris, G. Fratesi, G. Fugallo, R. Gebauer, U. Gerstmann, F. Giustino, T. Gorni, J. Jia, M. Kawamura, H-Y Ko, A. Kokalj, E. Küçükbenli, M. Lazzeri, M. Marsili, N. Marzari, F. Mauri, N. L. Nguyen, H.-V. Nguyen, A Otero-de-la-Roza, L. Paulatto, S. Poncé, D. Rocca, R. Sabatini, B. Santra, M. Schlipf, A. P. Seitsonen, A. Smogunov, I Timrov, T. Thonhauser, P. Umari, N. Vast, X. Wu, and S. Baroni, "Advanced capabilities for materials modelling with Quantum ESPRESSO," J. Phys. Condens. Matter, 29 465901 (2017).

61. G. Kresse and J. Hafner, "Ab initio molecular-dynamics simulation of the liquidmetal-amorphous-semiconductor transition in germanium," Phys. Rev. B., 49, 14251 (1994).

62. G. Kresse and J. Furthmüller, "Efficiency of ab-initio total energy calculations for metals and semiconductors using a plane-wave basis set," Comput. Mater. Sci., 6, 15 (1996).

63. S. Grimme, "Semiempirical GGA-Type Density Functional Constructed with a LongRange Dispersion Correction”, J. Comput. Chem., 27, 1787 (2006).

64. G. Kresse and D. Joubert, "From ultrasoft pseudopotentials to the projector augmented-wave method," Phys. Rev. B., 59, 1758 (1999).

65. P. E. Blochl, "Projector augmented-wave method," Phys. Rev. B., 50, 17953 (1994).

66. D. Vanderbilt, "Soft self-consistent pseudopotentials in a generalized eigenvalue formalism," Phys. Rev. B, 41, 7892 (1990).

67. Ultrasoft pseudopotentials for $\mathrm{H}, \mathrm{C}, \mathrm{O}$ and $\mathrm{Al}$ atoms were taken from the Quantum ESPRESSO PseudoPotential Download Page: http://www.quantum-espresso. org/pseudopotentials(files: H.pbe-rrkjus.UPF, C.pbe-rrkjus.UPF, O.pbe-rrkjus.UPF and Al.pbe-n-rrkjus_psl.0.1.UPF), (2018).

68. A. Kokalj, "XCrySDen - a new program for displaying crystalline structures and electron densities," J. Mol. Graph. Model., 17, 176 (1999).

69. M. Poberžnik, D. Costa, A. Hemeryck, and A. Kokalj, "Insight into the Bonding of Silanols to Oxidized Aluminum Surfaces," J. Phys. Chem. C, 122, 9417 (2018).

70. C. Lanthony, J. M. Ducéré, M. D. Rouhani, A. Hemeryck, A. Estève, and C. Rossi, "On the early stage of aluminum oxidation: An extraction mechanism via oxygen cooperation," J. Chem. Phys., 137, 094707 (2012).

71. M. Digne, P. Sautet, P. Raybaud, P. Euzen, and H. Toulhoat, "Hydroxyl Groups on $\gamma$-Alumina Surfaces: A DFT Study," J. Catal., 211, 1 (2002).

72. D. Costa, T. Ribeiro, F. Mercuri, G. Pacchioni, and P. Marcus, "Atomistic Modeling of Corrosion Resistance: A First Principles Study of $\mathrm{O}_{2}$ Reduction on the $\mathrm{Al}(111)$
Surface Covered with a Thin Hydroxylated Alumina Film," Adv. Mater. Interfaces, 1, 1300072 (2014).

73. T. J. Kloprogee, L. V. Duond, B. J. Wood, and R. L. Frost, "XPS study of the major minerals in bauxite: Gibbsite, bayerite and (pseudo -) boehmite," J. Colloid Interface Sci., 296, 572 (2006)

74. J. Landoulsi, M. J. Genet, C. Richard, K. El Kirat, S. Pulvin, and P. G. Rouxhet, "Evolution of the passive film and organic constituents at the surface of stainless steel immersed in fresh water," J. Colloid Interface Sci., 318, 278 (2008).

75. P. Marcus and J. M. Grimal, "The anodic dissolution and passivation of Ni-Cr-Fe alloys studied by ESCA," Corros. Sci., 33, 805 (1992).

76. A. W. Ralston and C. W. Hoerr, "The solubilities of the normal saturated fatty acids," J. Org. Chem., 7, 546 (1942).

77. T. Liu, S. Chen, S. Cheng, J. Tian, X. Chang, and Y. Yin, "Corrosion behavior of super-hydrophobic surface on copper in seawater," Electrochim. Acta, 52, 8003 (2007).

78. H. Knoezinger and B. Stuebner, "Adsorption of alcohols on alumina. 1. Gravimetric and infrared spectroscopic investigation," J. Phys. Chem., 82, 1526 (1978).

79. R. Ngongang, E. Marceau, X. Carrier, C.-M. Pradier, C. Methivier, J.-L. Blanc, and M. Carre, "Surface passivation of aluminum alloy 6061 with gaseous trichlorosilane: A surface investigation," Appl. Surf. Sci., 292, 165 (2014).

80. L. Wang, I. Siretanu, M. H. G. Duits, M. A. C. Stuart, and F. Mugele, "Ion effects in the adsorption of carboxylate on oxide surfaces, studied with quartz crystal microbalance," Colloids Surf. Physicochem. Eng. Asp., 494, 30 (2016).

81. D. M. Taylor and G. F. Bayes, "The surface potential of Langmuir monolayers," Mat. Sci. Eng., C8-9, 65 (1999)

82. G. Avitabile, R. Napolitano, B. Pirozzi, K. D. Rouse, M. W. Thomas, and B. T. M. Willis, "Low temperature crystal structure of polyethylene: Results from a neutron diffraction study and from potential energy calculations," J. Polym. Sci. Polym. Lett. Ed., 13, 351 (1975).

83. S. Ramachandran, B.-L. Tsai, M. Blanco, H. Chen, Y. Tang, and W. A. Goddard, "SelfAssembled Monolayer Mechanism for Corrosion Inhibition of Iron by Imidazolines," Langmuir, 12, 6419 (1996).

84. A. Ulman, An Introduction to Ultrathin Organic Films: From Langmuir-Blodgett to Self-Assembly, Academic Press, 2013.

85. D. M. Taylor, "Developments in the theoretical modelling and experimental measurement of the surface potential of condensed monolayers," Adv. Colloid Interface Sci., 87, 183 (2000).

86. J. M. Castillo, M. Klos, K. Jacobs, M. Horsch, and H. Hasse, "Characterization of Alkylsilane Self-Assembled Monolayers by Molecular Simulation," Langmuir, 31, 2630 (2015).

87. M. Poberžnik and A. Kokalj, "Implausibility of bidentate bonding of the silanol headgroup to oxidized aluminum surfaces, App. Surf. Sci. (2019) accepted for publication.

88. F. Chiter et al., in preparation, (2019).

89. I. Malavasi, I. Bernagozzi, C. Antonini, and M. Marengo, "Assessing durability of superhydrophobic surfaces," Surface Innovations (2015).

90. P. Rodič and I. Milošev, "One-step ultrasound fabrication of corrosion resistant, selfcleaning and anti-icing coatings on aluminum," Surf. Coat. Technol. (2019) accepted for publication. 